\title{
Review \\ Potential of Demand Response for Power Reallocation, a Literature Review
}

\author{
Emmanuel Binyet ${ }^{1}{ }^{1}$, Ming-Chuan Chiu ${ }^{2}$, Hsin-Wei Hsu ${ }^{3, *}{ }^{\circ}$, Meng-Ying Lee ${ }^{4}$ and Chih-Yuan Wen ${ }^{2}$ \\ 1 Research Center for Environmental Changes, Academia Sinica, Taipei 11529, Taiwan; \\ emmanuelbinyet@hotmail.com \\ 2 Department of Industrial Engineering and Engineering Management, National Tsing Hua University, \\ Hsinchu 300044, Taiwan; mcchiu@ie.nthu.edu.tw (M.-C.C.); nttcps5@gmail.com (C.-Y.W.) \\ 3 Department of Industrial and Systems Engineering, Chung Yuan Christian University, \\ Taoyuan 320314, Taiwan \\ 4 Green Energy Initiative Division, Industrial Technology Research Institute, Hsinchu 310401, Taiwan; \\ mengying.lee@itri.org.tw \\ * Correspondence: hwhsu@cycu.edu.tw; Tel.: +886-32654421
}

check for updates

Citation: Binyet, E.; Chiu, M.-C.; Hsu, H.-W.; Lee, M.-Y.; Wen, C.-Y. Potential of Demand Response for Power Reallocation, a Literature Review. Energies 2022, 15, 863. https://doi.org/10.3390/en15030863 Academic Editors: Javier Contreras and Carlos Henggeler Antunes

Received: 28 November 2021

Accepted: 21 January 2022

Published: 25 January 2022

Publisher's Note: MDPI stays neutral with regard to jurisdictional claims in published maps and institutional affiliations.

Copyright: (C) 2022 by the authors. Licensee MDPI, Basel, Switzerland. This article is an open access article distributed under the terms and conditions of the Creative Commons Attribution (CC BY) license (https:// creativecommons.org/licenses/by/ $4.0 /)$.

\begin{abstract}
The power demand on the electric grid varies according to the time of the day following users' needs and so does the cost of electricity supply because the electricity mix is formed using different generators of varying capacities. Demand response (DR) is the modification of the consumption load curve following a signal from the electricity provider; it is mostly used for peak clipping. By reducing the short-term mismatch between generation and consumption, it helps to integrate intermittent renewables and new low-carbon technologies such as energy storage, electric vehicles, and power-to-gas. The present work is a literature survey based on the following keywords: demand response, demand technology, potential, power, and power dispatch, which aims to provide a summary of the state of the art regarding the potential for demand response implementation. Literature is either related to potential assessment or to implementation; less focus is given on non-dispatchable DR than on dispatchable DR. There is a great untapped potential for power demand reallocation in all sectors. Incentivizing users to participate in demand response programs is crucial, as well as education campaigns and smart meters penetration. The barriers to demand response are mostly the investment costs in the absence of an adequate pricing scheme.
\end{abstract}

Keywords: demand response; load scheduling; renewable energy integration; peak shaving; smart grid; energy management system

\section{Introduction}

"Demand response (DR) is a tariff or program established to motivate changes in electric use by end-use customers in response to changes in the price of electricity over time, or to give incentive payments designed to induce lower electricity use at times of high market prices or when grid reliability is jeopardized" [1]. The measures taken on the demand side (demand-side management, DSM) aim to reduce the peak load and shift the load to a time frame when the demand is lower. DR plans offer numerous advantages to the electric grid, the electricity provider, the industry and services, and to the consumers. The main advantage is the reduction of the peak-to-average ratio (PAR) and the avoidance of additional investments in power generation, supply, and distribution systems for peaking, thus reducing the costs on the power supply side [2]. The demand response strategy aiming to reduce peak-time consumption is called peak clipping; reducing the peak consumption also decreases emissions and the overall energy consumption. Demand response also alleviates the pressure on the electricity grid and on the utility companies. The grid also becomes more reliable; in case of a sudden surge in load or an emergency, the electricity price would be less likely to dramatically increase. Consumers can choose demand response 
procedures that suit them in order to reduce their electricity bills. Demand response is significantly limited by societal, technical, economical, and legislative barriers [3]. Most of the programs in place only concern large industrial consumers while households and commercials are slowly being integrated [4]. Power systems face reliability issues, lower efficiencies, energy losses, and high emissions [1]. Under a traditional flat rate price of electricity, there is no incentive to change the consumption pattern while power generation costs vary throughout the day. Consequently, the mismatch between the retail price and the wholesale price reduces the overall efficiency. Demand response can reduce the need for operating expensive peaking generators through rescheduling of the energy usage to off-peak periods [5]. The same power management plan applied for the peak load can be used to balance the supply and demand in order to provide more stability and reduce the fluctuations in demand. DSM can regulate the energy consumption of the smart environment in order to significantly reduce energy wastage, peak load demand, and the corresponding monetary costs [6]. DSM strategies involve energy efficiency (EE) measures as well as DR strategies. They aim to reduce energy wastage to the minimum during operation, manufacturing, or servicing, thus bringing appreciable financial gains. The main difference when implementing a DR strategy is that the demand pattern is modified according to the electricity price signals or according to the state of the grid.

The present study is a review of publications within the field of demand response according to several keywords. Recent findings concerning the DR potential in all sectors are reported. The current limitations and the future evolution of demand response are also mentioned. Finally, the interaction between demand response and technologies such as artificial intelligence (AI), internet of things (IoT), blockchain, product-service system (PSS), and big data is also elaborated. The second section of this paper gives a summary of the literature focused on DR potential estimation and also describes the research on optimization of demand response procedures. The third section describes the research trend within the different aspects of demand response. The fourth section points out areas for further research.

\section{Literature Review}

According to Tranfield [7], system literature review (SLR) is a reproducible, structural, transparent, and thorough selection procedure. Therefore, the SLR method was used to select 81 research papers published between 2010 and 2020.

In a first search phase, a list of keywords such as demand response, demand techniques, potential, electricity supply, and power dispatch was entered. To remove biases as much as possible and extend the scope, major online libraries were included, for instance: Science Direct, Engineering-Village, and Web of Science. The search results were refined to include articles and conference proceedings. The publication date ranged from 1 January 2010 to 31 December 2020. The keyword "demand response" generated 56,532 matches; adding the important keyword "potential" reduced the number of matches to 8942 and when the scope was further reduced by adding the keyword "electric", 1458 articles remained. By tuning with different keywords such as "manage", "schedule", and "control", it yielded 120, 242, and 612 articles, respectively. Using a combination of "manage", "schedule", and "control + optimize" $(120+242+57)$, a total of 419 articles remained; which were all read to write the present review. The focus was on journal papers and conference proceedings while aiming to discover all the published material in the field. Although the search included three different libraries, most of the matches came from Web of Science. Among the 419 articles we came across, only the publications with more significant contributions based on potential and application were kept to form the core discussion of this review. Finally, 81 studies were selected and are cited in the present work.

\subsection{State of the Art of DR Participation Methods}

DR programs usually rely on a mechanism incentivizing the consumer to reduce consumption in order to limit peak load. When the client takes part in demand response, 
there are mainly three methods to change electricity consumption: (1) reducing the load and the energy consumption, (2) shifting the electricity consumption to a different time frame, (3) limiting the reliance on the grid by using auxiliary power sources. For example, (1) by reducing the lighting, ventilation, and air conditioning/heating intensity as a peak shaving strategy; (2) operation of home appliances and industrial processes can be postponed to night or to a period in between peaks in order to profit from less expensive tariffs; (3) strategies involving auxiliary solar panels and batteries, wind or hydro turbines, or recollection of waste heat (from furnaces) for generating electricity. All these means can reduce or even remove the need for the grid during the demand response period. The clients can be categorized according to Siano [8] as:

- $\quad$ Large commercial firms and industries (CI);

- Small commercial firms and industries (CI);

- Households dwellings;

- Personal electric vehicles (PEV);

- PEV fleets.

Large CI customers usually involved in manufacturing processes can invest in technology allowing to accurately control the loads and thus have the opportunity to become involved in wholesale or retail electricity markets. The load in commercial facilities is mostly that of heating, ventilation, and air-conditioning (HVAC), which can be used for DR. Residential customers have small loads from home appliances and HVAC; they can be involved in direct load control (DLC) programs. However, motivation for investment in energy management systems is low; this tendency is likely to change with the introduction of advanced metering infrastructure (AMI) and building automation systems. Electric vehicle penetration is a challenge for the grid and the utility as uncontrolled charging can damage equipment and cause voltage problems. On the other hand, when the charging is aggregated and controlled, the PEV fleets can be seen as mobile batteries and thus present a great opportunity for load shifting. Up to now, there have been relatively few studies on the potential of the electric load modulation. Müller and Möst [9] analyzed the possibility and flexibility of DR integration into the German renewable energy sources (RES) system. The results show that DR reduces the curtailment of renewables (35-77\% in their model) and reduces the need for storage and backup generators. On the other hand, the benefits of DR are mostly seen for shorter term fluctuations because extended periods of surplus or shortage require storage or backup. According to Müller and Möst, the time slot is critical when assessing DR capacity; in the case of Germany with a DR potential reaching 23-30\% of the total consumption, only 5-8\% can be curtailed during the peak period. Ali et al. [10] investigated the potential of DR for indoor temperature regulation throughout the seasons in households. Their simulation results showed that there is huge potential for reducing energy consumption from the HVAC system load. Rotger-Griful et al. [11] did experiments on a 12-story apartment building where they investigated the demand response potential for ventilation purpose under the northern European climate. Their results showed that when 796 residential buildings of similar size to the test building are aggregated, the power consumption can be reduced by $1.57 \mathrm{MW}$ (about $2 \%$ ) during the 6 p.m. -7 p.m. time slot.

Samad et al. [12] investigated some DR applications in the industry, for instance, an aluminum manufacturing plant where the load is adjusted according to the market. Through installation of an energy management system (EMS), the electric load is controlled using a load control (LCPD) system. The benefits from implementing DR were reported as USD 700,000. Amy's Kitchen, a company in California, US, took part in PG and E's (Pacific Gas and Electric Company, San Francisco, California, USA) automated demand response (ADR) program which transmits price and reliability information to large commercial firms and industries. The power companies use openADR to inform one day ahead the users concerning the DR events schedules. EMS activates the preprogrammed DR strategy, for example, turning off certain freezers and battery chargers as well as raising the temperature of the freezers and refrigerators. 


\subsection{DR Research Fields}

Within the scope of DR research, 81 papers published over the last 10 years (2010 to 2020) were reviewed. The literature on DR potential can be categorized as shown in Figure 1:

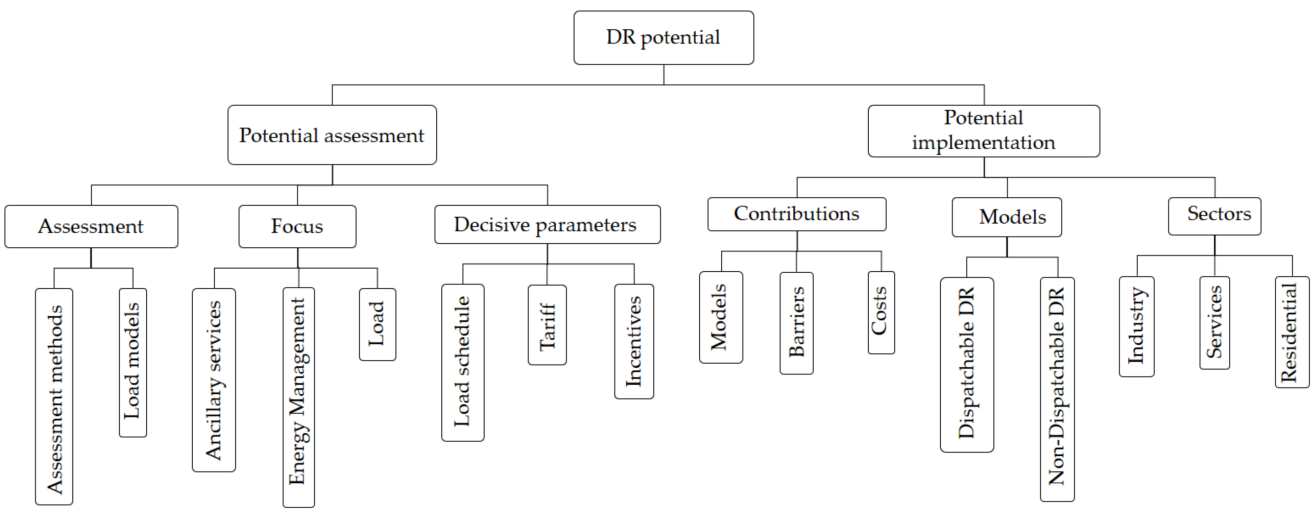

Figure 1. Architecture of the different areas of DR potential studies.

The demand response potential can be split into two categories: assessment and implementation. In potential assessment category, literature can be further characterized by their assessment methods, focus, and decisive parameters. In the implementation category, literature can be characterized by types of contributions, models, and sectors. In general, each article is subcategorized into more than one group; an Excel table was used to keep track of the matches. This analysis is useful to describe the trend of demand response research and highlight areas that may have received less attention. Literature on DR is very extensive and includes various domains such as: societal concerns and incentivizing mechanisms, mathematical modeling for load scheduling optimization, AI for automated DR under 5G telecommunications framework, network voltage control, appliances control, etc. The present paper focuses on reviewing DR potential related research rather than on more technical aspects of DR.

\subsection{Potential Assessment}

Potential assessment is the basis of a demand response plan and the first step for promoting demand response. DR potential assessment is very important for maximizing the benefits of DR. Potential assessment related studies estimate how much the peak load can be reduced; peak load reduction is the most important contribution of DR as it allows for reducing the need for expensive peaking plants. According to the statistics from the US-based independent system operators' regional transmission organizations (ISO/RTO) [13], the reduction of peak demand through DR ranges from $1.4 \%$ to $4.1 \%$. For instance, implementing DR reduces the summer peak, and in 2008, the largest peak reduction reached $38 \mathrm{GW}$. The Federal Energy Regulatory Commission (FERC) [14] stated that in 2019 the peak load could be reduced from 38 to $188 \mathrm{GW}$, representing $4 \%$ to $20 \%$ of the peak value. It is worth noticing that if DR is fully deployed, the load reduction equals the estimated electricity consumption increase for the next ten years. In the US, potential assessment-related studies are often focused on ancillary services provided by DR participants and on energy management for load shedding and scheduling. The key parameters for increasing the potential and participation are the electricity pricing schemes, rewarding incentives, and ability to schedule the load.

\subsubsection{Potential Implementation}

Forty-three of the 81 papers selected mentioned different models for implementation. The present work sorted the publications from the last decade and it appears that the modelrelated studies can be split into three categories: potential assessment methods, potential implementation models, and load models. Studies focusing on potential implementation 
describe actual or hypothetical implementation of DR in the different sectors and report results from collected or modeled data, then draw conclusions. Those studies highlight the difficulties to overcome and the costs for unleashing full DR potential. Studies mostly focus either on dispatchable DR allowing maximum flexibility or on non-dispatchable DR for low flexibility applications.

In potential assessment methods, Heitkoetter et al. [15] used a model for load-shifting potential to calculate in each area the load-shifting cost curve and also assessed the potential of 401 administrative districts in Germany. For each district, the median of the cumulated load increase of all technologies is $25 \mathrm{MW}$ through avoidance of curtailment. Moreover, using a model to calculate the load-shifting cost curve, Xu et al. [16] proposed a distributed generation system coupling electricity storage for an industrial park. Their demand response model is based on the day-ahead real-time pricing DARTP. The customer can rearrange consumption for the next $24 \mathrm{~h}$ accordingly; the model is based on a price elasticity matrix (PEM). According to their results when comparing the DARTP model and a model without DR, the overall costs were reduced by $3 \%$ and $16.7 \%$. Bego et al. [17] used an approximation method to obtain the optimum solution and carried out a numerical study to demonstrate the efficiency of their method using a non-linear mathematical model that can minimize the electricity consumption costs as well as the hidden costs of not attaining the production targets. Among the implementation model references, Cui et al. [18] proposed two virtual electricity generation plants models: one virtual power plant (VPP) based on time restriction and incentive demand response IBDR-VPP and one based on probabilistic CBDR-VPP, and created an optimized model based on a bi-level code. The upper level represents the coordination of operations for maximum profits. The lower level simulates the day-ahead market clearing process done by a regular system operator. Their model describes how public utility companies that participate in an advanced electricity market can maximize profits. Parizy et al. [19] proposed a new demand response technique aiming to lower the PAR and the retail price of electricity and at the same time without taking away from the comfort of the end users. This method relies on one-way data communication to protect the secrecy of the users. Their model uses a hopping scheme to plan consumption for the equipment with flexible schedule. It does not need individual consumption of the appliances, thus reducing the communication between the control center and the consumer, which saves significant bandwidth costs. Ghazvini et al. [20] proposed a calculation method for a power management system applied to smart homes which follows a demand response algorithm regulating household expenses. They gave simulation results for different electricity prices and demand response algorithms. The average power costs of the households decreased from $29.5 \%$ to $31.5 \%$. De Angelis et al. [21] developed a model based on mixed integer linear programming that finds the best solution according to the real-time power and heat constraints. It can operate not only under static conditions but also under dynamic conditions and therefore keeps continuity in the task and thermal comfort in between the regulation periods. Measured data were used to perform computer modeling and their results proved the efficiency and robustness of the method.

Li et al. [22] used a research method based on an electric load model and built a mathematical model that describes in detail the electricity demand and the consumption mode giving the load curve of the residential sector in Singapore. They proposed a kind of demand response management (DRM) plan and built a benchmark for testing their home SG and assessed the peak load reduction from DRM. They demonstrated the efficiency of DRM plans. Tang and Wang [23] developed a model predictor control (MPC) method using the predicted value from the model. For a sudden DR event, it optimizes the operating system of the refrigerators and air conditioners. The water cooler of the air conditioning system is partially shut down to provide the grid with means to reduce consumption in case of emergencies. The results show that the MPC method can efficiently perform optimum control of two refrigerators between DR events and demonstrate power consumption reduction together with a relatively comfortable indoor environment. 


\subsubsection{Focus}

When attempting to categorize research related to demand response, and because each study focuses more or less on a different aspect around which revolves the argumentation, five main keywords stand out: demand response, ancillary services, power management, load, and others. "Energy Management" can be linked to $41 \%$ of the literature, "Load" to $34 \%$, "Ancillary Services" to $19 \%$, and "Others" to $6 \%$, as shown in Table 1.

Table 1. Keyword architecture within the selected demand response literature.

\begin{tabular}{cccc}
\hline Energy Management & Load & Ancillary Services & Others \\
\hline $41 \%$ & $34 \%$ & $19 \%$ & $6 \%$ \\
\hline $\begin{array}{c}\text { Management of } \\
\text { coneration and }\end{array}$ & $\begin{array}{c}\text { Electric power on the } \\
\text { grid, real-time power } \\
\text { on the system }\end{array}$ & $\begin{array}{c}\text { Ensure secure and } \\
\text { stable operation of } \\
\text { the power system, } \\
\text { guarantee the } \\
\text { electricity supply } \\
\text { while maintaining } \\
\text { constant voltage and } \\
\text { frequency }\end{array}$ & $\begin{array}{c}\text { Research work not } \\
\text { relevant to the } \\
\text { previous categories }\end{array}$ \\
& & \\
\hline
\end{tabular}

In the different demand response keyword categories, Ghazvini et al. [20] gave an incentive program for households taking part in demand response and used it as an input in their household (home) energy management system (HEMS) model. Then they gave simulation results for different tariffs and DR procedures to demonstrate the role and efficiency of the HEMS. Qayyum et al. [24] used mixed integer non-linear programming (MINLP) to schedule the appliances (based on real load patterns) for a mid-size home under time-of-use (TOU) pricing within a microgrid configuration with a grid connection and a $3 \mathrm{~kW}$ solar PV system. In this configuration, surplus electricity generation can be sold to the grid. They considered a minimized peak load and a minimized electricity cost configuration, which were successful in doing so. Aalami et al. [25] focused on interruptible/curtailable services (I/C) and capacity market programs (CAP). They used the 2007 Iranian grid peak day-load curve for their simulation work. With the concourse of a strategy success index, they compared the simulation results from different scenarios to determine the priority order between those. Bego et al. [17] designed a demand response procedure for manufacturing industries using a mathematical model based on a mixed integer non-linear programming method aiming to reduce electric bills to the minimum and to minimize potential costs ensuing from production not reaching the target.

Concerning research related to ancillary services, Brown et al. [26] reviewed the role played by demand response in six wholesale electricity markets within Australia's National Electricity Market (NEM). They proposed that to trigger DR, full transparency of the electricity price should be established so that consumers would modulate their energy expenditures accordingly. Price-responsive loads are economically sounder; however, investment in real-time telemetering equipment is needed. They mentioned that in terms of ancillary services, load curtailment yields lower response time to a surge than generators. This highlighted the fact that within the capacity markets, the DR participants are paid to be available for load curtailment in case of emergencies. Shoreh et al. [27] describe the ancillary services programs through which industries partake in DR. Indeed, participation in DR can be done through the energy market or the ancillary services market. Spinning reserve and regulation are the main ancillary services; regulation is the near real-time continuous balancing of load and generation which requires frequent and accurate dispatch. While in the energy market, only load curtailment during peak periods is of interest. Load curtailment gives a quicker response than starting up or even ramping up a thermal power plant. Loads that can be cycled on and off quickly, such as smelters, water heaters, heat pumps, dual-fuel boilers, pumping stations and air compressors, refrigerated warehouses, 
freezers, air conditioners, and hot water reservoirs, can all provide ancillary services. Spinning reserve is the portion of the generation capacity that is unloaded but synchronized to the grid and that can be dispatched within $10 \mathrm{~min}$; the non-spinning reserve is the capacity that can be synchronized and ramped up within $10 \mathrm{~min}$. Shoreh et al. cited that processes involving larger loads, such as aluminum and chloralkali electrolysis, cement mills, wood pulp production, and electric arc furnaces, were shown to be able to provide $50 \%$ of the non-spinning reserve of the global balancing market in 2020. Spinning reserves can be provided by smelters. Industrial participants can earn rewards when providing spinning reserve by curtailing their load; one of the first countries to involve the industrial loads in ancillary services was the UK. Shoreh et al. also gave a detailed list of the industrial processes where DR has been implemented. Valdes et al. [28] compared the energy policy of Germany and Chile in order to assess the potential and challenges of demand response applied to productive industry and gave directions for promoting demand response in Chile. They mentioned that industrial DSM is both cost effective and easy to implement. As a matter of fact, the German government has been promoting industrial DSM since 2015 within the Electricity Market 2.0 scheme. Policies required for triggering DSM can be listed as voluntary (energy efficiency certifications, use of new technologies), regulatory (obligations to meet standards), financial (loans and subsidies), or market based. Regarding the policies in the EU, they cited the Third Electricity Package and Smart Meters Operation Act, which focus on smart meter penetration of $80 \%$ by 2020 by requiring their use for facilities consuming more than $6000 \mathrm{kWh}$ yearly. They concluded that the key lies in combining DR with energy efficiency (EE) policies because reducing consumption is simpler, more cost-effective, and requires less investments than DR. Regarding Chile, a regulatory framework including incentives and obligations must be created to trigger EE reforms and participation of the demand-side in the balance-market. They also mentioned that demandside flexibility is important for reaching higher penetration rates of intermittent renewables. Considering Chile, they highlighted the fact that the transmission and distribution networks need to be expanded to allow renewable electricity dispatch from zones where there is surplus to those in deficit; storage facilities owned by third parties are also a requirement and thus will allow development of future business models. Karlsen et al. [29] presented a method relying on energy costs that provides information to public utility companies and users. Their work assesses the incentive given by different dynamic pricing schemes. They produced a thorough and complete analysis allowing the end users, public utilities, and policy makers to solve the problems of demand-side management. This involves deep renovation of old buildings, especially in terms of insulation regarding electric heating. Martin et al. [30] mentioned that real-time pricing is the most efficient pricing structure for demand response programs and therefore used it in their simulations. They used the software IDA-ICE to model the HVAC demand response of one floor of an educational office building. An algorithm controls the space heating and ventilation according to the room temperature, $\mathrm{CO}_{2}$ concentration, and electricity price signals. Their DR algorithm brings more thermal comfort $\left(21^{\circ} \mathrm{C}, 50 \%\right.$ of the occupied time) and electricity savings than setting a constant room temperature of $20^{\circ} \mathrm{C}$.

In the energy management category, $\mathrm{Hu}$ and Xiao [31] proposed a new DR control method based on a model meant to automatically control residential inverter air conditioning units according to the day-ahead electricity price compared to the baseline scenario. This model-based optimized control system can still provide thermal comfort and reduce the overall consumption costs during a DR event and reduce the peak consumption. Amrollahi and Bathaee [2] investigated the ability of DR programming for optimizing microgrids. To optimize the components size, they used a DR program for a wind and solar electricity supply which can provide better matching between the consumption and generation profiles. DR utilization reduces the need for power electronic units on the microgrid and thus decreases the equipment costs. Ren et al. [32] presented a HEMS based on price forecasting and aiming to reduce the electricity bills. The system is composed of a price forecasting model, a load planning algorithm, and an energy consumption monitor. Olsen et al. [33] 
carried out an analysis of a cement factory to assess the possibility for demand response implementation, load reduction or shifting, and increasing energy efficiency. Results show that $\mathrm{DR}$ is a great asset for cement factories, which are very energy intensive. Indeed, the large grinding mills have a significant demand response potential because they involve non-continuous processes that can be interrupted. The example of a cement plant following incentives from public utilities to modify its electricity consumption was also given.

In the load category, Klaassen et al. [34] analyzed the potential of scheduling washing machines and showed the evolution of the load with time. They obtained the support of many households concerning flexible utilization of the washing machines and advice on which design functions could boost the flexibility. Rieger et al. [35] used the generation and consumption data from 201 households in Texas for the year 2014. They used a load scheduling calculator to support the two-part pricing plans: real-time retail price and capacity-pricing. The results showed that aggregate DR can bring more savings than individual DR. Toriti et al. [36] investigated Europe's single person households. They used the HETUS database to obtain the usage time schedules in order to build a usage curve and to determine the peak for single person households. Finally, they displayed the difference in the usage rates of 15 European countries. Alimohammadisagvand et al. [37] used the dynamic building simulation software IDA Indoor Climate and Energy together with their DR-control algorithm in the case of a Finnish two-story detached house. They aimed to minimize both the electricity consumption of the heating system and costs while maintaining high levels of thermal comfort. The heating system includes a heat pump and a hot water storage tank which delivers heat in the rooms through the floor; a ventilation system with heat recovery is also included. The inputs of the control algorithm are the hourly electricity price, the minimum indoor temperature, the outdoor temperature, the domestic hot water (DHW) temperature, the building thermal characteristics, and the HVAC system characteristics. When the electricity price and the minimum temperature set points are above a certain threshold, the heating system is turned off. They concluded that energy savings and cost savings of around $11 \%$ can be achieved.

\subsubsection{Key Parameters}

The decisive parameters of demand response can be listed as load schedule, tariff, incentives, and others. From a thorough review of the last 10 years of demand response research, narrowed to 81 publications, 42 papers (33\%) listed load schedule as a key parameter. The research papers having electricity price as a decisive parameter represent $24 \%$ of the references (31 articles). Twenty-three papers stipulated incentives as a key parameter, representing $18 \%$. Sixteen papers $(13 \%)$ listed implementation potential and barriers. Seventeen papers were listed in the "others" category, representing $13 \%$. Figure 2 shows the distribution of the decisive parameters mentioned in the selected literature. References often list several decisive parameters; therefore, the number of occurrences exceeds the number of references.

In the load schedule category, Heitkoetter et al. [15] determined the load-shifting potential and the related costs for 401 districts in Germany and stated that demand response through load shifting can reduce the curtailment of renewable energy in periods when renewable generation exceeds demand. They disclosed their data and Python source code used to determine the regional load-shifting potentials in Germany. They modeled load shifting as an electricity storage operation and listed in detail the potentials and loadshifting costs for different home appliances, power-to-heat, cooling, ventilation, electric vehicles, and power-to-gas that includes power-to-hydrogen and power-to-methane plants and various industrial processes. Their results were appended to a map of Germany giving a spatial distribution of the load increase potential that could be used in case of surplus renewable energy generation. Results show that the greatest potential is for electric heating, followed by home appliances, and lastly, industry and services consumption load. In most cases, load-shifting technological costs are lower than the average subsidy costs for curtailment of renewable energies, therefore incentivizing the government to invest in load- 
shifting technologies. Pereira et al. [38] proposed a new type of demand response model for smart grids that is based on the fuzzy subtractive clustering method. It can automatically reduce the load of home appliances. Hence, at peak load times, the utilization is reduced accordingly, thus stabilizing the electricity supply. Rodriguez et al. [39] introduced a new tool for analyzing cost efficiency of DR strategies implementation. The ultimate objective is to reduce the impact of intermittency of renewable generation sources on the grid. Finally, they shared and discussed the results of their dynamic modeling and showed the potential and benefits of demand response algorithms in the paper manufacturing industry. Yi et al. [40] built a multiobjective robust scheduling DR model considering renewable energy uncertainties that aims to provide the lowest operation costs and highest renewable energy utilization while maintaining power balance. The inputs of the model are the external power output, renewable energy output, load demand, and DR output. The constraints are system power balance, renewable energy, and demand response output. Their results show that DR can effectively smooth fluctuations in renewable energy supply and consequently increase the utilization rate of renewables. Amrollahi and Bathaee [2] used an approach in which the flexible load can be suppressed or shifted in order to reduce or eliminate the mismatch between electricity supply and electricity consumption. This allows for optimizing the power units on the grid, thus reducing the related costs. This kind of demand response algorithm will not reduce the overall consumption but only the usage time. DR implementation reduced the peak consumption by $36.8 \%$, and the consumption load factor increased by $57.9 \%$.

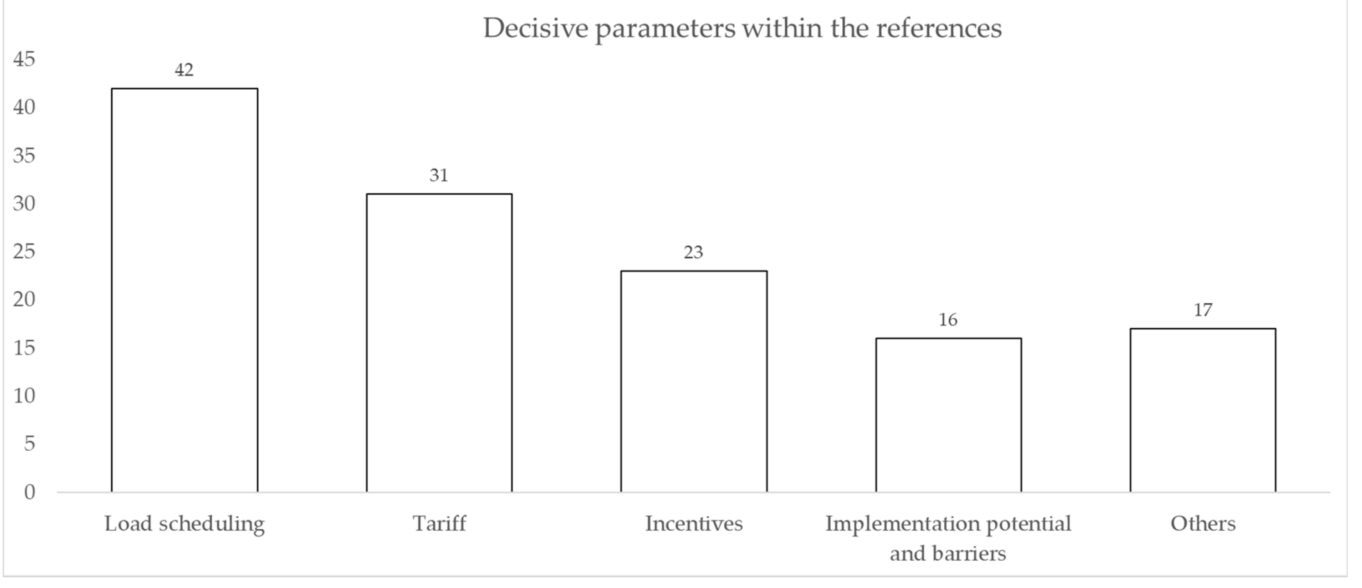

Figure 2. Distribution of decisive parameters within the references.

Among the literature listing the tariff as a decisive parameter, Good [41] used a demand response model considering behavior economics. He investigated how the energy costs and the time necessary for thermal comfort of inhabitants influence the peak electricity price offered by the grid operator. The purchaser of demand response (electric company) should promote and advertise for DR participation which is a prosocial behavior. Yalcin et al. [42] investigated the case of water transfer stations and showed that through DR control, electricity usage and electricity bills could be reduced. Electricity fees were lowered by $58 \%$ resulting from a better system design that is more efficient with less energy wastage. Nilson et al. [43] detailed the different opinions of the households concerning demand response strategies and how the incentives could increase the participation of the consumers. Their results show that compared to environmental incentives, price incentives are the most appropriate because it is the most efficient strategy to support the flexibility of the demand. Tahir et al. [44] showed the necessity for demand side management and estimated the reforms in the demand response strategies to be made by the electricity department to promote demand response planning. Tahir et al. mentioned that DR development in Asia is far behind Europe or the US; they described the DR programs and the pilot projects in place in China. According to them, the barriers to DR implementation are having a 
centralized electrical system, lack of education programs, low difference between peak and valley prices, few incentives, no return on investment for companies taking part in DR, limited availability of smart metering infrastructure for communication with the utility company, and absence of automated load control installations for smart homes. Among their propositions to overcome these barriers, they believe that aggregators could have a major impact as those would serve as mediators between the utility companies and the consumers by informing consumers on the DR benefits and giving detailed load shedding estimations to utilities. With the increased availability in small-scale local intermittent RE generation and the gradual transition towards a smart grid, the numbers of small capacity prosumers increases. These need to be aggregated to reach minimum capacity for market bidding. In other words, prosumer participation in the electricity market relies on aggregators. Both flexibility and generation can be traded on the market. Consequently, aggregators, by increasing the market exposure of prosumers contribute to reaching climate change mitigation objectives. They will officially (according to the EU electricity directive [45]) be new independent stakeholders in the European electricity markets.

In the research work category focusing on incentives, Cobelo et al. [46] detailed a project in Spain, relying on economic rewarding of participating users aiming to change the consumption habits of small and medium size companies in order to control the peak load. Sharifi et al. [47] proposed a demand response model based on economic theory and mathematical methods, following TOU pricing. To increase their profits, the consumers can shift a part of their consumption from a period where the electricity price is peaking to a period in between peaks. Apart from reducing the flaws of DR models based on price elasticity, the proposed model includes the possibility of different responses from different types of consumers having different flexibility levels. Märkle-Huß et al. [48] used the measured data from the Austrian and German electricity markets to determine the effect of demand response on the electricity spot market price and on the load. The results show how the price fluctuations harm the users with non-flexible systems. Being able to shift $25 \%$ of the load could have saved 500 million Euros, which represents $6 \%$ of the local electricity market. Pricing schemes incentivize the user to voluntarily participate in demand response. Eid et al. [49] described the different billing methods used for this purpose: DLC requiring demand control, real-time-pricing, critical-peak-pricing, peak-time-rebates and time-of-use pricing requiring smart metering and price display. Peak-time-rebates schemes also require the baseline consumption curve. DLC is easier to implement as it gives the user no freedom concerning the interruptions; participants are rewarded for their participation in the form of an electricity bill discount. Kohlhepp et al. [50] mentioned that when the participants allocate their HEMS/HVAC for fast system balancing during very short duration events (seconds), not enough value can be given using the aforementioned pricing methods and thus contractual incentives should be used instead. Indeed, if the flexibility allocated to the grid by the participant cannot be significantly monetized, then there is no incentive for the demand side to engage in DR. Jayantilal and Shah [51] summarized the load management techniques on the supply and demand side for non-linear load. In order to bring more energy savings, they investigated replacement of equipment and power factor corrections (PFC) techniques. They also proposed using automated control of the demand and advised that more research should be performed on load management strategies of the customers.

\subsection{Potential Implementation}

Demand response has been vastly adopted around the globe; load clipping measures have already been established in many countries. Several researchers have investigated demand response implementation focusing on the contributions of DR and on the type of users. The following section describes the literature on demand response potential implementation and the state of the art. 


\subsubsection{Contributions}

The research contributions can be classified as models, implementation, barriers, potentials, and costs. As described in Figure 3, most of the literature is focused on models and the works on costs and barriers are limited.

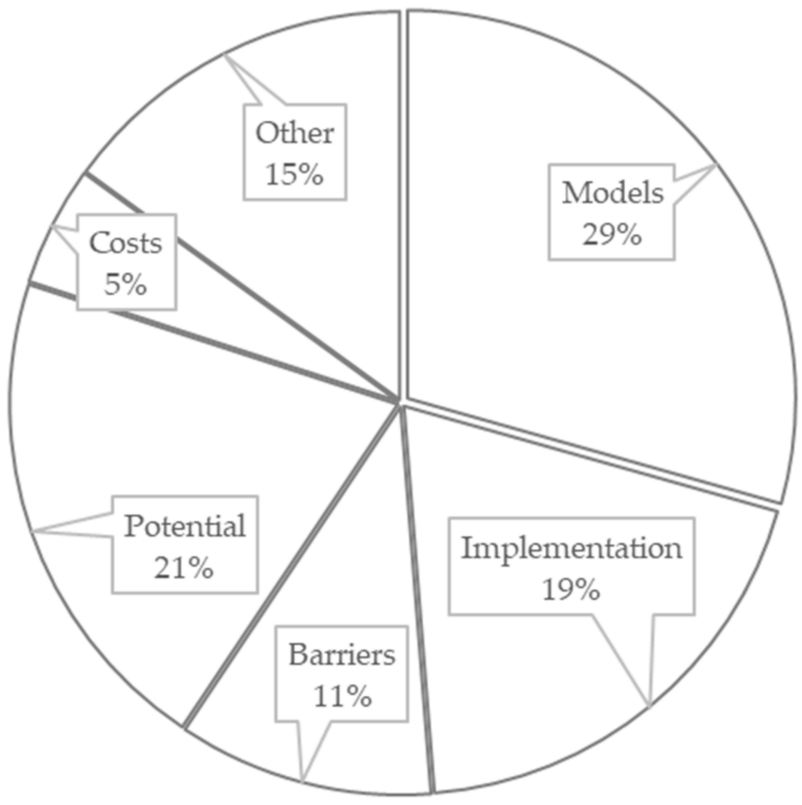

Figure 3. Areas of contributions within the selected demand response literature.

Within the DR model contributions, Xu et al. [16] proposed a model for the electricity supply of an industrial park making the most of distributed generation and electricity storage. Compared to standard DARTP demand response models and models not including demand response, the present method reduces the costs by $3 \%$ and $16.7 \%$. Märkle-Huss [48] used measured data from the German-Austrian electricity market to calculate the effect of demand response on the electricity spot market and on the load. Their results show that in 2014, 25\% of the load could have been shifted to save 100 million USD. Müller et al. [52] investigated the results of large scale deployment of demand response for more than three hundred dwellings equipped with heat pumps. Based on the meter data and the outdoor temperature measurements, an automatic flexible electricity consumption program was built with thermal expansion valve heat pumps that can be throttled to reduce the overall load by $40 \%$ to $65 \%$. The load reductions can be aggregated with a median absolute percentage error of below $7 \%$. The results show how to quantify and predict the system's demand response potential. Bui et al. [53] proposed an EMS for multimicro grids (MMG) based on a multiagent system (MAS) and thus avoiding unnecessary trades with the public electricity grid, hence reducing the costs of operating microgrids and multimicrogrids. Yao et al. [54] proposed a real-time charging plan coordinating charging of electric vehicles incorporating a demand response program in a design parking lot where two kinds of DR programs are implemented while meeting the necessary charging level for the EV. They mentioned that more savings could be achieved by increasing the electric vehicle car fleet.

Concerning contributions related to barriers, Taipower Engineering [55] performed an inquiry on the consumption of its larger customers in order to know their characteristics and understand how they individually control the peak loads and finally for learning about their desire to participate in demand response programs. Stede et al. [56] analyzed the role of aggregators (intermediates between the electricity market and the participants) in promoting demand response in the industry. Their results show that the core role of an aggregator is to promote knowledge on demand response potential and support implementation within key participants. Valdes et al. [28] investigated the case of Germany and Chile where they reviewed and compared the respective energy policies. They laid out 
the difficulties for the manufacturing industry to unleash its demand response potential. Eid et al. [49] mentioned that installing smart meters, in-home devices, and other DRrelated equipment is expensive and requires an investment; ideally the investment costs should be split between the actors benefiting from DR along the supply chain. They also mentioned that instead of valley filling, another peak could be created in valley hours. This can become a concern since the industrial sector in Europe accounts for a third of the European electricity consumption; therefore, large implementation of demand response will impact the entire electricity system. Moreover, since coal generation is less expensive and more emission intensive than gas generation, load shifting can induce higher greenhouse gas emissions. This is precisely another reason for the implementation of a carbon tax. Shoreh et al. [27] mentioned that the main barrier to demand response in the industry is that processes are interdependent and often require very precise timing; thus, interruptions could cause failure to reach the production objectives. Moreover, due to the significant consumption of manufacturing plants, battery-based storage systems are not economically feasible. Shoreh et al. listed some of the main barriers to DR in the industrial sector: lack of implementation of time-based rates, weak incentives, reduced electricity sales lowering the revenue of the utility companies, lack of aggregators, and no standard communication platform between DR participants, utilities, and wholesale markets.

Regarding the research on potential, Vuelvas and Ruiz [57] gave an analysis on the Cournot competition between generators (considering thermal and hydro) when an incentive-based demand response plan is in place where users curtail their demand upon request. Each generator aims to maximize its profit by anticipating the resulting market price; thermal generation costs are modeled with a quadratic function while hydropower generation costs are considered fixed. The profit of each generator, which is the difference between the generation costs and the electricity selling price, becomes an optimization problem. The Karush-Kuhn-Tucker conditions for all electricity generators must be solved simultaneously to resolve this interrelated optimization problem and find the Nash-Cournot equilibrium. They assessed the potential costs (profit reductions) of implementing DR and concluded that IBDR can reduce consumption in a cost-effective fashion.

\subsubsection{Models}

Demand response is basically split into two kinds: dispatchable demand response and non-dispatchable demand response. The selected 81 references published during the period 2010-2020 can be sorted into $80 \%$ dispatchable demand response and $20 \%$ nondispatchable demand response related. To explain this tendency, dispatchable electric demand is easier for modeling and for carrying out experimental studies. In dispatchable $\mathrm{DR}$, the user surrenders control of some of his consumption load to the electricity provider in exchange of a reward for participation (DLC). In non-dispatchable DR, the user is provided with electricity prices signals and is free to choose to curtail his load or not. In this case, consumers react to prices and disregard the system's state.

Concerning dispatchable demand response, Aalami et al. [25] proposed interruptible/curtailable services; thus, the users can be charged according to their own usage and obtain discounts or waivers if agreeing to reducing the load in case of sudden demand response events. In capacity market planning, the clients guarantee to provide the agreed upon load reduction in case of a sudden demand response event. If the clients fail to meet the terms, a penalty is given. Torriti et al. [58] proposed a few incentives to make users lower their consumption. For instance, in Spain, since 1988, around 200 users that have demand exceeding $5 \mathrm{MW}$ benefit from a special price. The electricity supplier can request for $45 \mathrm{~min}$ up to $12 \mathrm{~h}$ of reduced demand depending on the different individual discounts of the users. In Italy "Interruptible Programmes" is designed for large companies; the participants must lower consumption to the preset values. In 2007, the amount of subsidies was set at 150,000 EUR/MW/year and every tenth interruption, $3000 \mathrm{EUR} / \mathrm{MW}$ were given as compensation. Deng et al. [5] inquired about the prerequisites of establishing a smart grid. The conditions under consideration for building the model are the user's 
consumption habits and load-shifting rules. It is important to notice that the mathematical problem can be expressed in several separate blocks: maximum usage, minimum costs, price forecasting, renewables, and storage. The main objective of this method is to schedule the usages times. Gils [59] specially focused on time usability and geographic distribution of flexible loads using the data collected from industrial production and electric consumption. Together with temperature-related periodic load curve, they estimated the amount of hours per year where load can be increased or reduced. The dispatchability is expressed by planning the electricity consumption reductions. Ozturk et al. [60] used decision making to support a system advising the optimum operating time for home appliances in order to allow consumers to save energy. The flexibility depends on the user's lifestyle. The potential schedule of operation of the home appliances is predicted and thus the aggregator is able to predict the client's demand.

Concerning research on non-dispatchable demand response, Amrollahi and Bathaee [2] investigated the case of a microgrid during a shortage of dispatchable energy sources and when only non-dispatchable renewables (wind and solar) are present, aiming to meet the energy demand. In order to reduce the mismatch between the electricity supply and demand, the load is reduced or shifted in time. This allows optimization of the size of the units and to reduce the related costs. Chuan and Ukil [61] built load profiles for housings of different sizes in Singapore and validated them with meter data from pilot housings in the campus of NTU. Bitaraf and Rahman [62] also argue that the curtailment of excess wind power generation can be mitigated by increasing the flexibility of the system either using storage or demand response. They propose that demand response should be scheduled such that the resulting rebound peaks match high wind generation. In their model, they considered a direct load control program with a grid having $20 \%$ wind power generation and the remainder met with thermal power plants. Their results showed that an overall $10 \%$ implementation of DR reduces the wind energy curtailment by $11 \%$; when scheduling compressed air energy storage and demand response, they concluded in a $40 \%$ reduction in wind energy curtailment. Dehnavi and Abdi [63] proposed a new optimized demand response procedure based on power transfer distribution factors (PTDFs), available transfer capability (ATC), and dynamic DC optimal power flow (DCOPF). This procedure improves the load curve.

\subsubsection{Demand Response within the Different Sectors}

When sorting the literature on demand response according to the respective sectors as shown in Figure 4, 58 of the 81 selected publications relate to the residential sector, 38 of the 81 selected publications relate to the industrial sector, and 17 papers within the selected literature were linked to the service sector. Some studies include several sectors in their analysis and that is why the total number of contributions over all the sectors exceeds the number of references.

In the residential sector section, Torstensson and Wallin [64] investigated the demand response potential of Swedish households. The household dwellings were categorized into apartments and single family house or townhouses. It appears that economic incentives as well as consideration from the environment are the motivating forces for the consumer crowd. They highlighted that to develop an even more flexible load for households, more services are needed for increased convenience. Pereira et al. [38] proposed a novel kind of demand response model based on a fuzzy clustering algorithm. One principle of the model is that the consumer has control over load management; the load capacity is computed from the user's appliances. The procedure can instantaneously reduce the load by controlling the home appliances to stabilize with the electricity supply. It strives to bring economic profits while considering the load shape and the need for consumption. Good [41] investigated how behavior economics can improve demand response models when demand is high for energy services that can be reduced (thermal comfort); they investigated how would the energy prices or the dependence on thermal comfort influence the peak price of the electricity system operator. Including behavioral economics in their demand response 
model, Nilsson et al. [43] proposed an interdisciplinary assessment framework. Taking into account the different reactions of the households to demand response strategies, this procedure was tested in 2017 within 136 Swedish households, showing the efficiency of demand response. The authors stated that environmental incentives are necessary to increase consumer participation. Singaravelan and Kowsalya [65] designed a minimum cost maximum power (MCMP) algorithm for an energy management system that can schedule home appliances efficiently in order to reduce costs and peak consumption. The algorithm does not take into account the proportion of load already shifted when scheduling equipment and also does not infringe on the comfort of users. Paterakis et al. [66] developed a MILP (mixed integer linear programing) model of a HEMS for scheduling appliances such as dishwashers, washing machines, electric water heaters, and air conditioners, and takes into account electric vehicle charge and discharge (vehicleto-home) together with solar panels and battery-based electricity storage system charge and discharge (ESS-to-home). The inputs of the model are the $24 \mathrm{~h}$ day-ahead hourly electricity price, the ambient temperature, the cold water temperature, the EV arrival and departure time, and the duty cycle of the dishwasher and washing machine. The purpose of the model is to allocate the maximum load during the time frame where the price is the lowest, thus minimizing power costs. Consequently, when many users use the same HEMS, a high power peak may occur during those time frames. Therefore, a power limitation scheme is put in place to prevent overload. Shakeri et al. [67] studied a HEMS model for switching appliances between battery supply and grid supply using smart plugs and considering price information inputs; the supply side includes the grid, solar panels, and batteries. Batteries charge during off-peak periods or when solar power is available. The goal is to minimize electricity consumption costs. The purpose of the battery usage is to provide more comfort while relying less on the grid. They used a thermal model of the building and also models for the state of charge of the batteries, solar panels, and the appliances. Every time an appliance is turned on, the algorithm checks the electricity price and makes the decision to connect the appliance on the grid or on the battery if the latter is available. The results of their simulations showed that for a twoperson household with 26 appliances, costs savings reach $20 \%$ and the electricity demand from the grid is also reduced owing to the solar panels. Hussain et al. [68] performed a thorough review of six DR research papers focused on the residential sector and gave a summary in terms of scheduler type, electricity pricing schemes, optimization problem type, renewables, uncertainties, communication requirements, forecasting techniques, and appliance types. These studies aim to optimize household scheduling using linear and non-linear programming; the objective is to reduce the electricity bills as well as the consumption peak-to-average ratio. The constraints are based on user comfort, appliance usage, windows, renewable energy generation, battery storage, and avoidance of rebound peaks during the off-peak period. The homes are equipped with smart meters allowing usage of price forecasting tools, which are then used to schedule consumption; some appliances are interruptible and some are not. Some studies show costs savings of $24 \%$ to $44 \%$ and a peak-to-average ratio reduction of $38 \%$ while another study showed that solar PV and battery storage could provide $50 \%$ of the household consumption. Jordehi [69] sorted the DR optimization algorithms into two families, as shown in Table 2. Their review work describes in detail the mathematical models used in DR. Demand response optimization problems typically relate to consumption being shut down or turned on in different time slots and therefore involves binary decision variables. Hence, mixed-integer linear or non-linear programming may be used for finding optimum solutions. With increasing numbers of decision variables, metaheuristic algorithms can obtain near optimal solutions in a reduced amount of time while oftentimes finding optimum solutions would require unpractical computing power. The ones that have been applied to DR are listed in Table 2; among them PSO is the most popular. However, Jordehi concluded that the current research effort in mathematical modeling of DR programs is insufficient as uncertainties, comfort, and emissions need to be properly accounted for. 


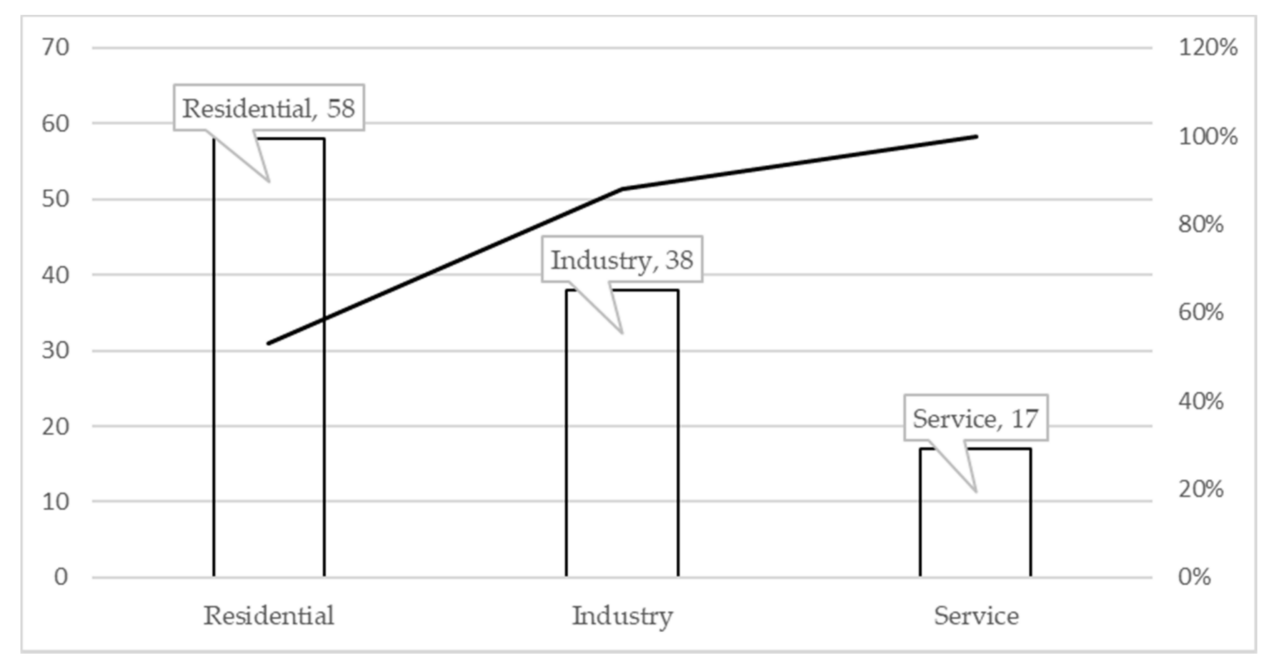

Figure 4. Selected literature on demand response categorized by sectors.

Table 2. Classification of DR optimization algorithms according to [69].

\begin{tabular}{cc}
\hline Classic Algorithms & Metaheuristic Algorithms \\
\hline Linear Programming (LP) & Particle swarm optimization (PSO) \\
\hline Non-linear Programming (NLP) & Genetic algorithm (GA) \\
& $\begin{array}{c}\text { Simulated annealing algorithm (SA) } \\
\text { Teaching learning-based optimization (TLBO) }\end{array}$ \\
\hline
\end{tabular}

In the industrial sector, Yalcin et al. [42] in their effort to reduce the electricity costs of a water transfer station through a DR plan realized that by pumping only at the appropriate times, the power can be reduced to $60 \%$ of the initial consumption, resulting in significant profits especially when the demand rises in summer. Vuelvas and Ruiz [57] proposed a novel demand response model based on incentives; they presented an analysis of the Cournot competition between generators when incentive-based demand response is in place. They proposed a new consumption curve customized to the client's preferences that can be used to predict the short-term consumption and set the wholesale price. This helps the grid operator to develop its operating system by integrating demand response into the electricity market. Pang et al. [70] gave an assessment on the load-shifting potential and realistic demand response potential for the manufacturing industry in the western part of Inner Mongolia. Based on the local industry load curve, they conducted interviews and investigated the potential of demand response using quantitative statistics. Starke et al. [71] quantified the potential for load flexibility in the industry according to the geographical location. Their results show that in the US, the industry can provide more than $12 \mathrm{GW}$ available for load flexibility. Liu et al. [72] highlighted the great demand response capability of data centers; indeed, those are automated and the equipment is constantly monitored but most importantly, the workload can be scheduled to be completed any time before a given deadline (hours to days). Workload could even be scheduled to match local renewable power generation. Liu et al. developed two algorithms for datacenters participating in coincident peak pricing programs aiming to shift load to minimize the electricity costs. They modeled the power supply as a microgrid composed of the public grid, backup generators, and solar panels. The backup generators are mostly fueled by diesel or natural gas, thus resulting in high emissions and indicating their use should be minimized. The power demand was modeled considering flexible batch workloads and non-flexible interactive workloads and also considering the cooling power demand using different cooling methods. Their Algorithm 1 minimizes costs based on coincident peak warnings predictions and 
their Algorithm 2 minimizes the worst-case cost. The algorithms provide $40 \%$ cost savings compared to the strategies already in place.

In the service sector, Gils [59] focused on the time availability and geographical distribution of flexible loads such as air conditioning, LED lighting, etc. Periodic and outside temperature-related load curves were considered in order to estimate the amount of load that could be reduced or added for each hour of the year. This analysis determined the demand response potential in all the consumption subsectors. Put all together, in a year, at every hour, $61 \mathrm{GW}$ of load could be shed for peak shaving and $68 \mathrm{GW}$ of load could be added for valley filling. Hui et al. [73] investigated the implication of the $5 \mathrm{G}$ telecommunication network and more generally the use of telecommunications in demand response applications and reviewed questions such as network safety, user's privacy, and reliability. They investigated the strengths of 5G in demand response and the related future implementation projects. To conclude, they listed the compulsory steps needed for 5G implementation in demand response. Dranka and Ferreira [74] performed a literature review on the methods for assessment of the different categories of demand response potentials. They also proposed a novel user-friendly and step-by-step theoretical framework that determines the demand response potentials. They aimed to create a structural approach providing consensus among potential estimations. Aryandoust and Lilliestam [75] mentioned that because of the net-zero carbon pledges in Germany by 2050, $80 \%$ of the electricity generation will be met with renewables and, for the most part, from wind and solar. They highlight the challenges of using demand response in a grid relying almost entirely on renewable generation as load can be only reconnected when there is excess generation, which could not be the case for extended periods of time. Consequently, they built a model where the various estimated loads are shifted from periods of lack of generation to excess generation, taking into account the constraints of load-shifting duration of the various consumers. Because the load cannot be shifted for extended periods of time, they concluded that DR is only useful for short-term balancing of the power system in a $100 \%$ renewable energy mix.

\section{Evolution of DR Potential}

After reviewing and categorizing 81 research articles published during the period 2010-2020, the number of articles sorted by publication year is plotted in Figure 5. The present work presents a cross-analysis on the categorizing of the references and thus revealed the trend of research on demand response potential.

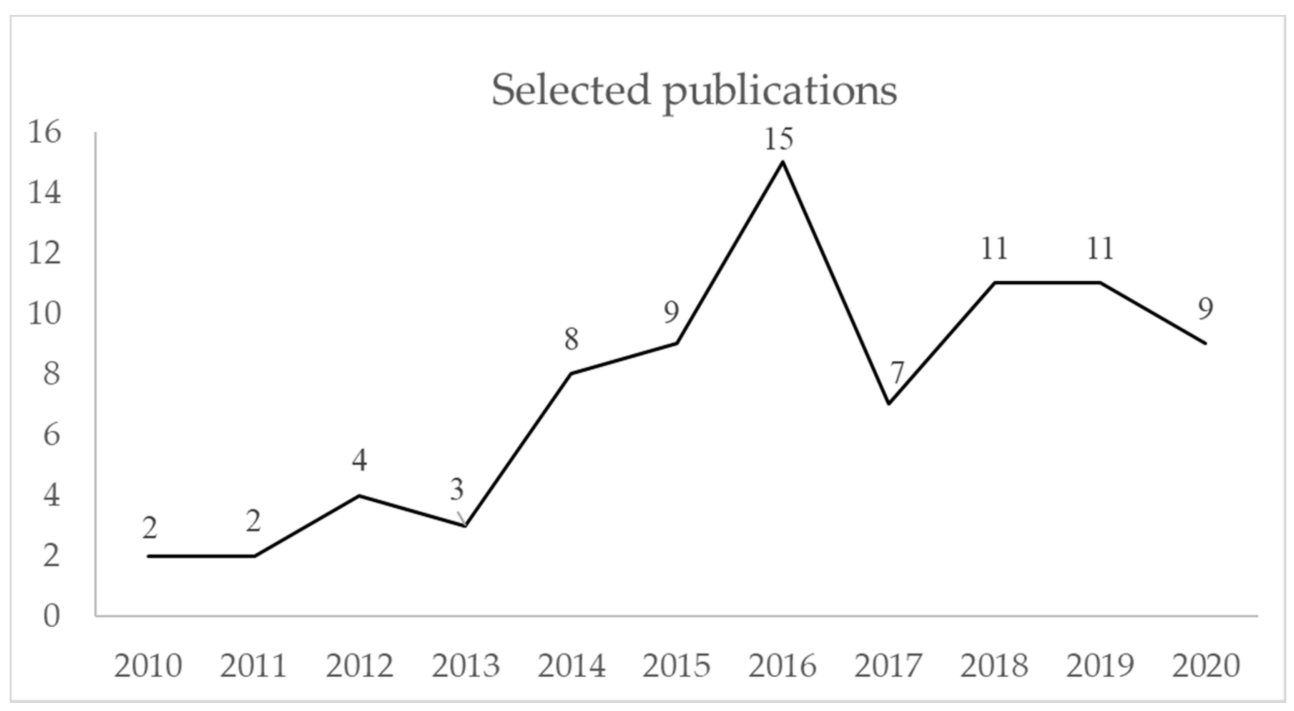

Figure 5. Selected publications sorted by publication year. 


\subsection{Trend of Implementation Sectors}

The models used in the literature can be characterized as potential assessment methods, implementation, and electric load models. The following subsections describe the literature on these subcategories. Ten years of selected research publications on demand response is summarized in Figure 6:

Others ¿.jPotential assessment

Potential implementation :..: Load

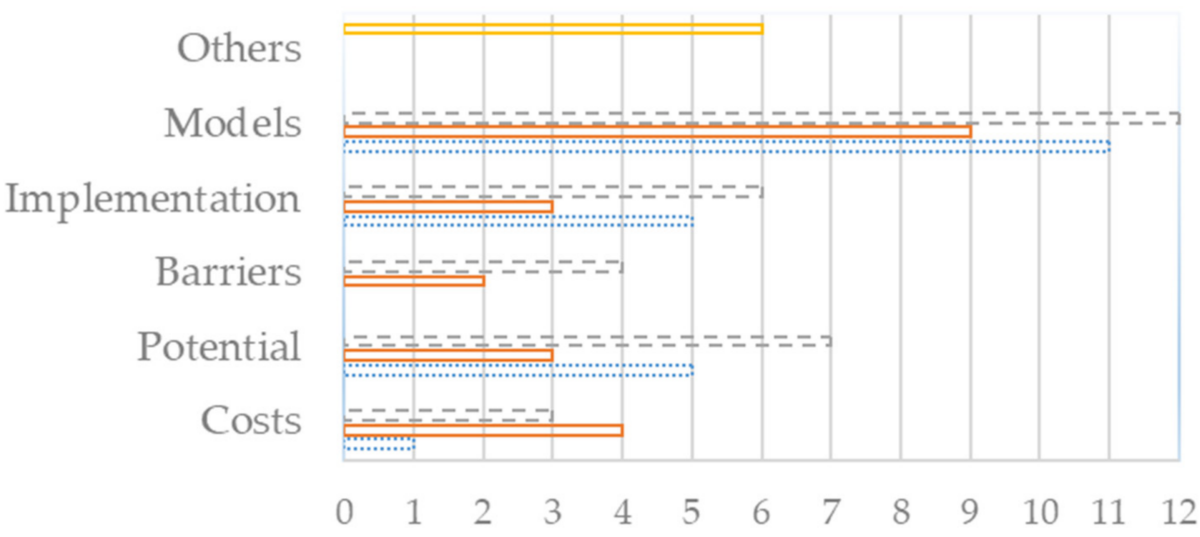

Figure 6. Distribution of the selected literature on demand response.

Most of the studies focus on modeling; the remainder is more evenly distributed into implementation, barriers, potential, and costs. Nilsson et al. [43] investigated the efficiency of demand response and how environmental incentives could raise the consumer's participation rate. Demand response implementation in 136 Swedish households in the year 2017 was tested. This gave field data for one year of Swedish DR. This research work covers barriers, implementation and modeling. It also gives advice on DR applied research and DR limitations. The future trends include technologies such as the IoT and the cloud. Hui et al. [73] explored the use of 5G communication networks and the role of telecommunications in demand response applications. Barbierato et al. [76] argue that demand response can act as a VPP which is a cost-effective way of managing the grid. They proposed a framework of three layers, namely: an advance multimetering infrastructure, an energy aggregation platform, and a real-time simulator. This is in order to manage the grid in real-time or to test the different DR policies in smart grids. They concluded that the main barrier to DR is the lack of regulatory framework and incentives.

Radenković [77] investigated the willingness of the consumers to participate in the new business models brought by demand response on the electricity market. The collected data allow for understanding the degree of acceptance of the users and help to design upgraded business strategies. They developed an internet-based DR business model suitable for developing countries where demand response has to be packaged as an ancillary service in order to be sold on both the wholesale and retail markets. First, an IoT infrastructure is needed for communication between the aggregator and the consumers; Wi-Fi enabled microcontroller devices have to be inserted into the power sockets (smart plugs) to give the aggregator control of the user's consumption. Different business models can be created depending on the consumers priorities (environmental protection, new technologies, or lower electricity bills). Surveys showed that consumer have more trust in governmentowned companies and thus a local distribution system operator (DSO) company should take the role of the aggregator. 


\subsection{Present State of the Keywords and Future Trend}

After sorting 10 years of research papers in the field of DR, the keywords on DR potential can be listed as energy management, load, and ancillary services as Figure 7. Some publications can involve several keywords in the same study. In the energy management category, most references proposed DR models; some are related to usage and potential. However, the literature on barriers and costs is scarce. The work giving a contribution on costs is that of Olsen et al. [33], which is an inquiry of the system in place for load shedding and shifting in a cement factory. Gholian et al. [78] built a model for energy intensive industries such as steel mills and gave solutions under smart pricing conditions for the control of the industrial sector's load. Solutions under day-ahead pricing, time-of-use pricing, and peak pricing have been presented. It appears that future research could be oriented toward the costs and barriers involved in energy management.

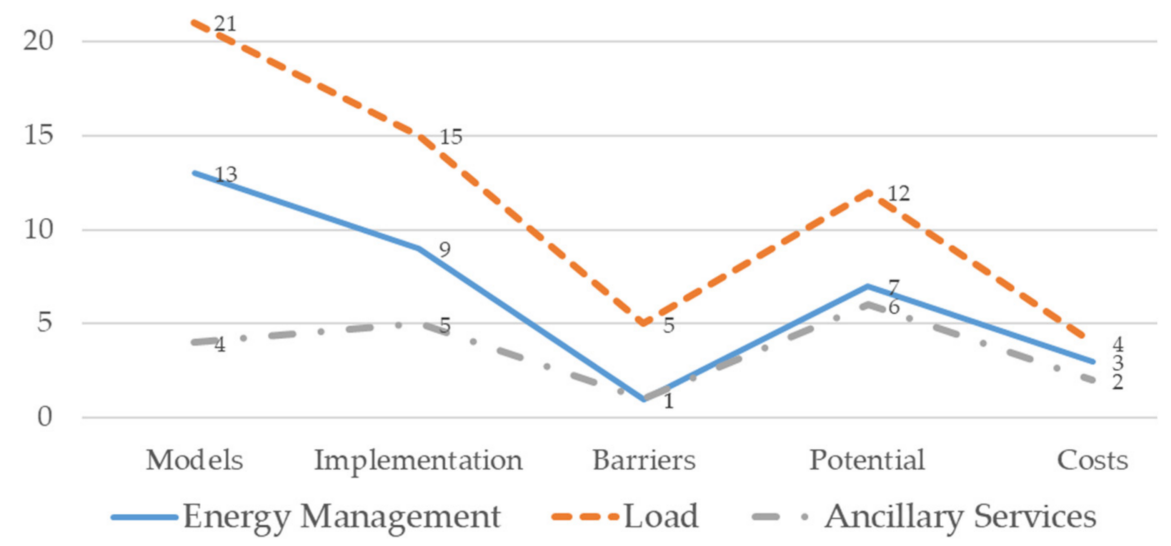

Figure 7. Distribution of keywords within the selected demand response literature.

Within the load category, cost and barrier related studies are fewer than modeling, implementation, and potential related articles. Compared to the energy management category, the tendency is similar. In the DR literature outside of energy management and load, the contributions are not strongly related to modeling, implementation, barriers, potential, and costs. For instance, Neves and Silva [79] compared three different demand response strategies aiming to bring flexibility to the energy system at the least cost. This in the case of Corvo Island (Portugal, small isolated island in the Atlantic Ocean) where the electricity demand is mostly for the residential sector (144 households) and the supply mostly comes from diesel generators and renewable microgeneration. They built models using MatLab for economic dispatch and electrification of domestic hot water, aiming to minimize generation and dispatch costs. They used a linear programming optimized demand response strategy aiming to satisfy hot water needs in a day with low solar radiation. Bossmann and Eser [80] argue that with the future grid being dominated by intermittent renewables, DR is important to smooth the transition and gradual penetration increase. They reviewed 117 publications on DR measures models; they categorized the studies into pricing schemes, electricity systems/markets, specific end-uses, and control strategies. They realized that DR control strategies related studies were scarce and that most of the literature is related to the US or Europe. They also highlighted the need for broader models including demand response, storage, grid expansion and flexible generation capacities; this in order to determine the optimal mix of flexibility options.

Vivekananthan et al. [81] highlighted that most studies ignored feeder voltage issues. Hence, they proposed an incentive-based DR procedure achieving peak shaving and also improving the feeder voltage profile. Customers are rewarded daily for their participation in the program. They also performed a case study where 30 houses were connected to a feeder. Network peaks were shaved and voltage violations were avoided.

Firouzmakan et al. [82] proposed an energy management system for a microgrid including renewables, micro-CHP (combined heat and power) units, and electricity storage 
that can implement demand response programs. Their algorithm capability was analyzed through simulation of a three-feeder microgrid resulting in lower natural gas consumption when in an islanding mode. Ghasemi and Enayatzare [83] proposed a management framework for an isolated smart microgrid involving wind and solar generation, incentive-based demand response, and pumped hydro storage. The optimization framework has forecasted generation and estimated hourly demand data as an input and outputs the scheduling of the pumped hydro storage unit and the operation costs which are to be minimized. Results showed that pumped storage is more efficient than demand response, although the whole system performs significantly better when demand response is added to storage.

\subsection{Development of $D R$ Considerations}

Currently, the research on the different DR assessment methods listed the main concerns as load schedule, pricing, and incentives as shown in Figure 8.

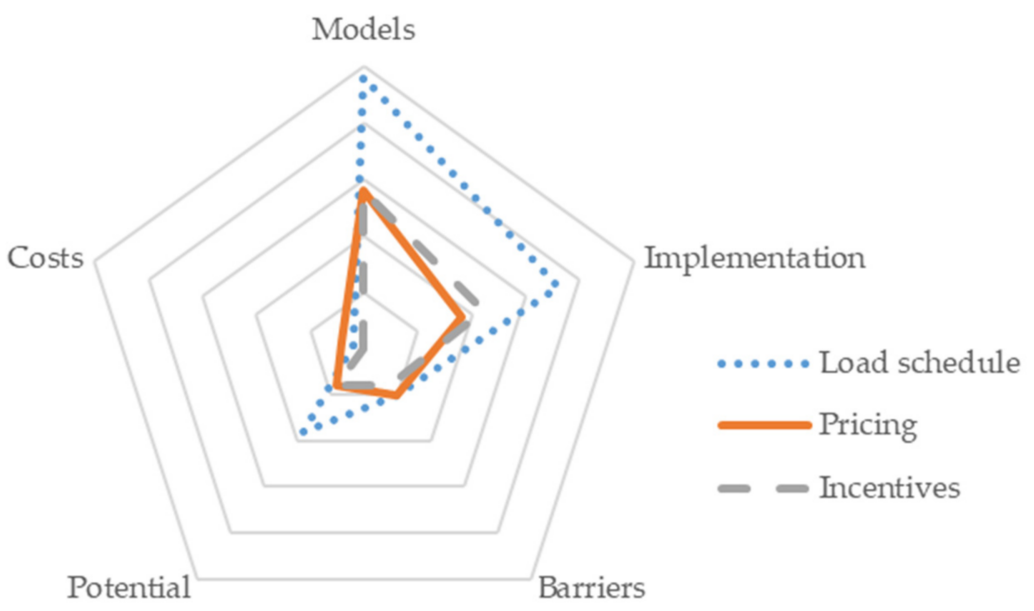

Figure 8. Distribution of the demand response key considerations within the selected references.

In the load schedule category, Heitkoetter et al. [15] determined the demand response potential of 401 German administrative districts and calculated the load-shifting cost curve. Cui et al. [18] created a two-level optimized model describing how public utility companies participating in advanced electricity markets can maximize profits. The upper level represents the coordination and the maximum profits. The lower level simulates the day-ahead market clearing. Derakhshan et al. [84] used the methods based on teaching learning-based optimization and shuffled frog leaping algorithms in order to propose an optimized model aiming to reduce the costs of consumption scheduling on smart grids. The results show that using demand response codes can reduce the costs and allow for more efficient use of the technology.

In the pricing category, Setlhaolo et al. [85] investigated residential demand response using scheduling of home appliances in order to minimize electricity consumption costs and obtain related rewards. Based on time-of-use pricing, they built a mixed integer non-linear optimization model. The optimal solution is a tradeoff between comfort and minimum costs; savings of $25 \%$ could be reached. Taipower [55] built a user database detailing the load characteristics as well as the electricity bills. Using averaging methods, a model of the daily load of each type of user was made.

In the incentive category, $\mathrm{Hu}$ and Xiao [31] proposed a model-based novel DR control procedure for residential inverter air conditioners that can automatically and in the most optimum way align their consumption according to the day-ahead price. Compared to the baseline scenario, the model-based control procedure can reduce the costs of consuming electricity during DR events or during peak periods while still providing enough thermal comfort. Rieger et al. [35] used the consumption and production data of 201 households in Austin (Texas) for the year 2014. They used a type of load scheduling algorithm supporting 
both real-time retail pricing and capacity pricing. The results show that DR coordination between households can bring more savings than individual DR.

\subsection{Development of the Types of DR}

Demand response can be split into dispatchable DR and non-dispatchable DR. Figure 9 shows the selected research work over the last ten years sorted according to key parameters; some studies involve several key parameters and keywords into their scope.

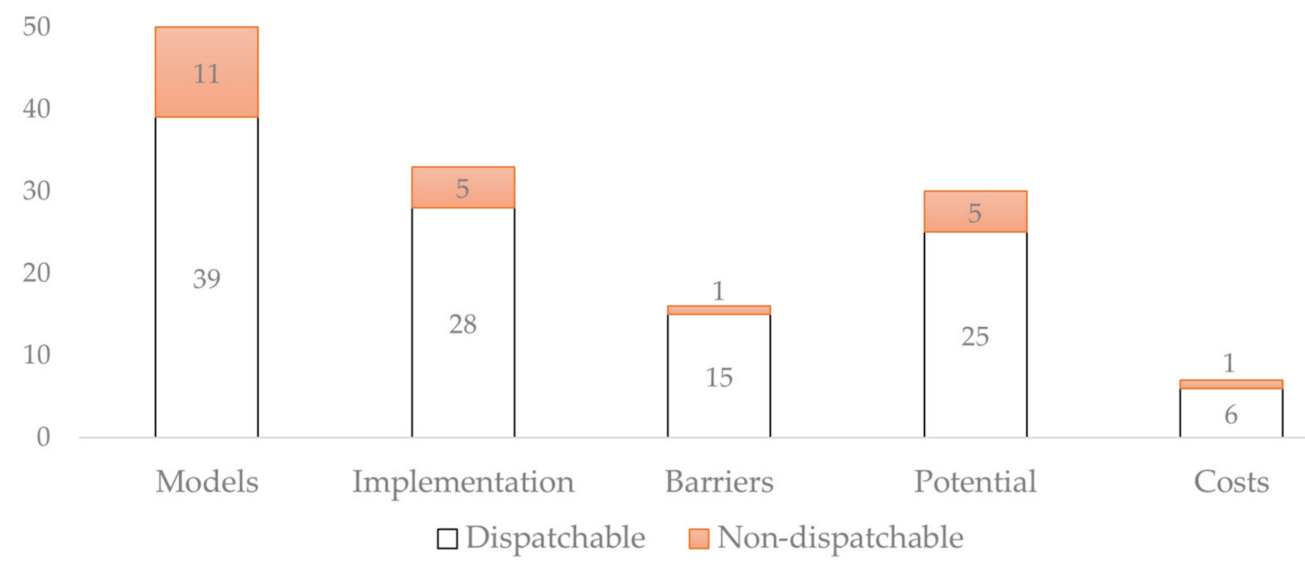

Figure 9. Distribution of the selected references according to the different areas of demand response.

According to Figure 9, the research on dispatchable DR is evenly distributed among the different subsections. For non-dispatchable DR, the research on DR costs and barriers is scarce. Olsen et al. [33] focused on the costs from non-dispatchable DR applied to a cement plant's kiln. He inquired about the equipment, operation limitations, and the amount of energy needed for the manufacturing process. He elaborated on cement plants changing their consumption habits following incentives from public utility companies. Pang et al. [70] investigated the case of the secondary sector in the western part of Inner Mongolia. They listed the barriers to load shifting and estimated the realizable potential. More research on costs and barriers in the field of non-dispatchable DR is needed to fill the gap.

\subsection{Trend of DR Research by Sectors}

Demand response is implemented in the residential, industrial, and service sectors. Figure 10 summarizes a cross-analysis of the last 10 years of selected demand response literature.

In the residential sector, most research focuses on modeling, implementation, and potential. Research articles falling in that category depict home appliances (water heaters, washing machines, electric vehicles) contributions to DR events. Moreover, they elaborate on modeling, forecasting, and control of equipment to assist with DR events. Studies also elaborate on how to actively influence DR-related incentives. On the other hand, in the residential sector, the contributions related to costs are only of $2 \%$ of the selected literature. Singaravelan and Kowsalya [65] used a MCMP algorithm to schedule home appliances. They compared their procedure and the currently available methods and it showed that without impairing on thermal comfort of the user while achieving tasks at a $100 \%$ rate, the consumption costs and the peak demand were reduced to the optimum level. Future research could be oriented towards costs in order to fill the gap in the residential sector DR area. 


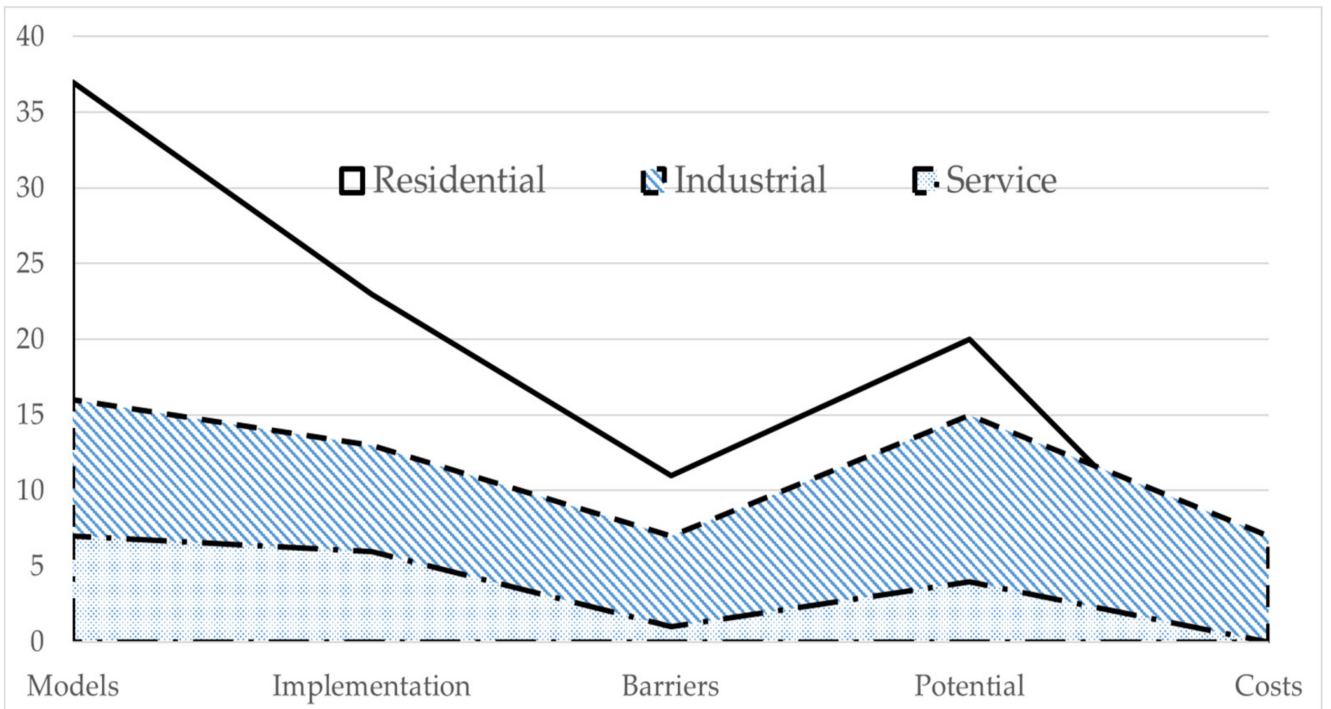

Figure 10. Selected literature distribution by sectors.

In the industrial sector, because of the production costs concerns, the DR research contributions are evenly distributed. The future research could also be focused on the obstacles and costs of DR. Finally, regarding research of DR in the service sector, in a similar fashion with the residential sector, contributions on costs are scarce. Moreover, the research on barriers is much fewer than in the residential and industrial sectors (with only $5 \%$ ). The future research trend could be focused on barriers and costs.

\subsection{DR Research in the Different Continents and Related Contributions \\ 3.6.1. Trend of Demand Response Research in Europe}

The demand response research according to geographic areas can be split into five subcategories: Europe, Asia, Americas, other regions, and "independent of location". The contributions of each subcategory were arranged into subsections. The trend of research in Europe is shown in Table 3. Accordingly, the DR research contributions in Europe are mostly about models, followed by DR potential, obstacles, others, and implementation. It is worth noticing that in the last 10 years most European DR research did not investigate costs. We can speculate that the electricity generation technology is more advanced in Europe and therefore research on costs was not prioritized compared to other subcategories.

Table 3. Trend of research on demand response in Europe.

\begin{tabular}{cccccccc}
\hline Contributions & Models & Implementation & Barriers & Potential & Costs & Others \\
\hline Number of publications & 17 & 8 & 10 & 12 & 0 & 9 \\
\hline
\end{tabular}

European research on DR use in industrial and residential sectors is mostly focusing on modeling and forecasting, assisted by studies on DR potential and barriers as shown in Table 3. The main barriers to DR implementation in Europe are the lack of incentives and the lack of consumer awareness. Advertisement campaigns together with the gradual penetration of smart meters shall contribute to the wide spreading of DR. Research works on actual implementation of models are few. If the DR research based on models could be put in practice through experiments or on-site data collection, it would bring a greater contribution to the architecture of smart grids for the residential, industrial, and service sectors. 


\subsubsection{Research Trend on Demand Response in Asia}

After having sorted the literature of this subcategory, the research trend in Asia is summarized in Table 4. Compared to the European subcategory, there has been less DR research work in Asia. Moreover, the contributions on barriers and potentials are much less than within European DR research. After survey, most research works come from China, which has been promoting SG and green energy in the recent years. The research contributions are evenly distributed between modeling, DR implementation, potential, and other DR subcategories. More articles are on DR models, implementation, and potential. Therefore, in Asia, research on costs should be considered. Apart from eastern Asia, implementation of DR in Southeast Asia is very limited. Cost-related DR research in Southeast Asia would contribute significantly to the development of DR in this region. The main barrier to DR implementation in Asia is the low return on investment probability due to the electricity pricing scheme.

Table 4. Trend of research on demand response in Asia.

\begin{tabular}{cccccccc}
\hline Contributions & Models & Implementation & Barriers & Potential & Costs & Others \\
\hline Number of publications & 10 & 7 & 3 & 7 & 0 & 7 \\
\hline
\end{tabular}

\subsubsection{Research Trend of Demand Response in the Americas}

After sorting research works into subcategories, Table 5 summarizes the trend of research in the Americas. It shows that the DR research in the Americas is distributed into modeling, implementation, potential, and costs. After analysis it appears that North America (Canada and the US) have mature DR technology and the resulting research is mostly about DR models, potential, and implementation. South America (Chile)'s DR technology is relatively underdeveloped and the research is mostly focused on overcoming the technological costs. In the future, research in North America will keep focusing on modeling and implementation and could also produce costs and barriers related studies. South American research could follow the North American direction and explore DR modeling and implementation technologies in order to overcome local limitations.

Table 5. Trend of research on demand response in the Americas.

\begin{tabular}{ccccccc}
\hline Contributions & Models & Implementation & Barriers & Potential & Costs & Others \\
\hline Number of publications & 11 & 9 & 3 & 6 & 6 & 1 \\
\hline
\end{tabular}

\subsubsection{Research Trend of Works on Other Regions and Studies Independent of Location}

After sorting the literature in this subcategory, the research trend in the "other regions" and in the "independent of location" subcategories are summarized in Tables 6 and 7. The DR research contributions in the "other regions" category are evenly distributed among the main topics. After a survey of the contributions, it appears that because of the vastness of the coverage, the research focus is similar. However, there are few presently available publications on modeling and implementation. Future research could focus on considering the different characteristics of each region when building models and analyzing practical implementation. The research independent to location focuses on modeling, implementation, and potential. Research works without specific location cannot produce accurate cost analysis because of the lack of credibility ensuing from not setting an implementation background. The future trend of DR research independent of location is to keep carrying out modeling, DR implementation, and potential analyses. 
Table 6. Trend of research on demand response in other regions.

\begin{tabular}{cccccccc}
\hline Contributions & Models & Implementation & Barriers & Potential & Costs & Others \\
\hline Number of publications & 2 & 3 & 2 & 4 & 1 & 6 \\
\hline
\end{tabular}

Table 7. Research works independent of location.

\begin{tabular}{cccccccc}
\hline Contributions & Models & Implementation & Barriers & Potential & Costs & Others \\
\hline Number of publications & 10 & 7 & 1 & 6 & 0 & 4 \\
\hline
\end{tabular}

\section{Future Evolution of DR Potential}

The present section discusses the observations made in Sections 2 and 3 and their implications in order to determine the future research opportunities and trend in the field of demand response. With the gradual penetration of smart meters and smart plugs and the popularity of mobile apps, and with increasing shares of intermittent renewables and electric vehicles, demand response will play a larger role for balancing short term fluctuations on the grid. Information and communication technologies (ICTs) contribute to upgrading the grid into a smart grid through two-way communication between consumers and providers. The smart grid is more stable and includes more renewables because it allows for efficient demand side management. The share of demand response and other flexibility measures will continue to grow in the future electricity grid; this is especially true with the growth of net-zero pledges. The aggregators will play an increasingly larger role as they give prosumers and smaller DR participants exposure to the electricity market, as depicted in Figure 11.

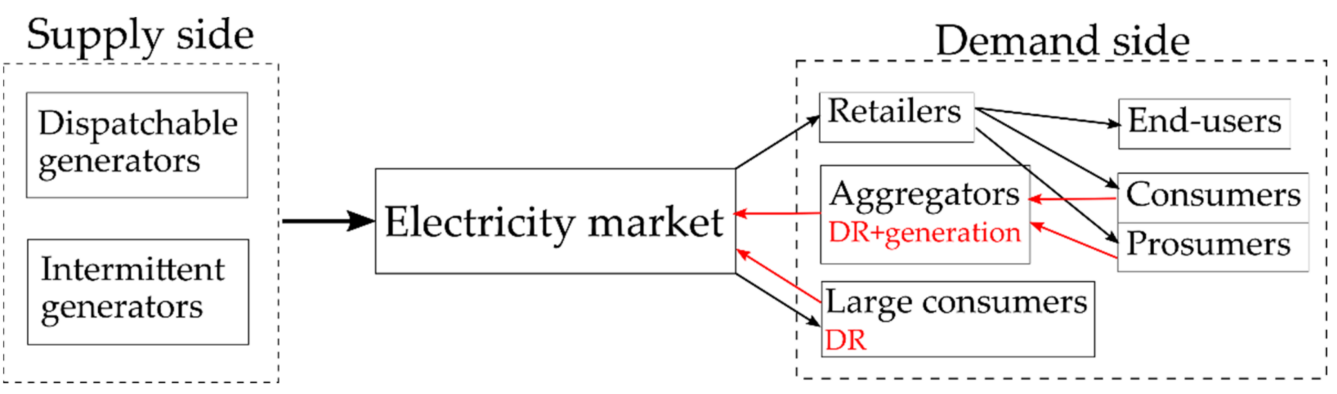

Figure 11. Aggregators' key role in the future electricity network.

\subsection{Artificial Intelligence Assisted Strategies}

Research is ongoing on algorithms aiming to increase the DR consumption-shifting capability and simultaneously accounting for different users' demand or even connecting the industrial, service, and residential sectors together. Within the same sector, the consumption from different users can be aggregated to increase the DR load-shifting capacity and obtain more rewards from the grid operators. The research scope includes the aggregation framework, single/multiuser DR algorithms and also the additional regulations needed when increasing the numbers of DR participants. Those are a few topics that researchers could explore in the future. Machine learning (ML) algorithms being part of AI show tremendous potential for DR applications. Reinforcement learning (RL) algorithms can learn from user feedback and consumptions patterns to enhance user satisfactions; optimal solutions are found through an iterative (training) process. Vázquez-Canteli and Nagy [86] described in detail publications focusing on RL in DR applications (HVAC, DHW, smart appliances, EV charging) and reported that Q-learning is the most common RL method used because of its simplicity. They also indicated that multiagent systems RL is still a theoretical field because RL algorithms were first designed for a single agent interacting with its environment. Indeed, DR applications require coordination of numerous interdependent agents simultaneously having an impact on the demand. Hence, the learning 
complexity increases accordingly. Thus, more research and field testing are needed on multiagent scenarios when electricity prices vary with the demand. AI is mostly used for load forecasting and automatic scheduling, which are highly complex tasks. ML can be used for load control thus automating the decision-making process. Antonopoulos et al. [87] conducted an intensive review of 160 papers related to ML/AI technologies applied to demand response; they gave a detailed description of the different AI techniques and algorithms that can be used for the different demand response strategies. Most of the studies they reviewed are related to the residential sector. AI can give a forecast of the generation and consumption curves involving uncertainty, automatically scheduling the devices while interacting with the consumer according to the real-time data, and therefore improving the stability and efficiency of the power system. The amount of data that will be generated by the massive deployment of smart meters will have to be managed using AI. Ensemble learning techniques, which consist of a prediction model built by combining several simpler base models, can give higher accuracy load forecasts than the base models.

\subsection{DR Influence on the Smart Grid and Big Data}

On the grid there are increasingly more users using demand response procedures. With the arrival of 5G network and 5G internet, DR can make use of new telecommunication technologies to control the demand side and to provide SG monitoring. Available DR methods require for the users' knowledge and approval because of various consumers' habits. This overall situation creates a significant barrier to DR. Future research could have a 5G network as a starting point to investigate the interaction between 5G architecture and demand response in order to find an optimum consumption curve that does not significantly impact the user's lifestyle. This would provide lower electricity usage costs while providing more comfort to the users. Esnaola-Gonzalez and Diez [88] mentioned in 2016 that the electricity consumption share of the residential sector was $17 \%$ in the European Union (EU). This highlights the untapped DR potential in the residential sector all over Europe, which is exactly what the RESPOND H2020 (integrated demand response solution towards energy positive neighborhoods) project targets. Funded by the H2020 program from the EU, RESPOND is being tested at three different pilot sites: Aarhus (Denmark), the Aran Islands (Ireland), and in Madrid (Spain). These sites have different characteristics such as climate, type of building, energy systems, and form of ownership. The key point contributing in the success of DR programs in the residential sector is user engagement resulting from the interaction with the end-user. This can be carried out using a mobile app. The RESPOND mobile app provides information such as humidity levels, temperature, appliance and window states (on and off, open or closed), and electricity consumption. As a result, a large amount of IoT data will be generated by the meters, sensors, actuators, and other devices, which then requires efficient management, storage, and querying. For instance, the use of smart plugs devices not only allows monitoring, but also on and off switching. Esnaola-Gonzalez and Diez detailed the procedure used by the RESPOND mobile app where building data are represented using semantic technologies and IoT data are stored in time series databases.

\subsection{DR Role in Sustainable Electricity}

The recent years have witnessed fast electric consumption increase, societal and environmental problems linked to the shrinkage of available natural resources. Therefore, there is a need for a sustainable electricity grid. Most countries have pledged to massively increase the share of intermittent renewables in their electricity mix; therefore, energy management is the foundation of a sustainable grid where DR has a major role to play. DR development has been hindered by technological, economical, and societal factors. The current research state on sustainable microgrids has not yet brought solution to the dilemma between economic profit and societal concerns, which would also require that both the consumers and electric companies benefit. To promote the development of low carbon communities, it is necessary to explore the interaction between the energy system 
and its beneficiaries and to strive for an energy management plan closer to the communities. At the same time, there is an intricate relationship between carbon pricing, DR, electric consumption, and the generated profits. The researchers could start focusing on demand response procedures for microgrids with multiple generators incorporating carbon pricing, DR strategies, electricity/heat networks, and storage systems.

\subsection{DR within Product-Service System}

Following the rise of $5 \mathrm{G}$ networks, edge computing architectures will retrieve great amount of consumption data and this might generate added value for the service providers. The consumption data from home appliance systems during DR events can be reused in the product-service systems. It is worth noticing that current DR and PSS research are carried out independently from each other. When DR is implemented under 5G architecture or PSS is done based on consumption data, future research will involve both fields. Kusumaningdyah et al. [89] argue that the energy market should be redesigned for renewable energy in order to efficiently balance demand and supply and create alternative revenues. Indeed, the main problem is that if wind and solar generation are peaking at the same time, the electricity generated must be sold at the same time in the absence of storage; this competition decreases the profitability of each generation technology. In their work, they evaluated the influence of including renewable energy into energy product-service systems (Re-EPSS). Within such framework, consumers buy services instead of products and thus the provider would have the control and management over the appliances. This would ensure maximized demand-side flexibility; however the consumers no longer own the appliances, which in itself is a barrier to EPSS development as society is rooted in product ownership. EPSS compared to EPOS (energy and product-oriented systems) makes more sense when considering the heating demand: consumers would pay for the service of maintaining the temperature above a certain minimum value instead of paying for the electricity fueling the heaters. Kusumaningdyah et al. created a Re-EPSS in retail electricity markets using a simulation-based design (SBD) framework; they analyzed the situations yielding the worst results in order to provide a more conservative approach allowing for uncertainties. Their market simulation involves an electricity generator and retailer, an appliance producer, and 100 households needing food preservation, heating and cooling, and laundry services. Consumers can choose to remain with the EPOS or to switch to the EPSS and choose between lower costs, better performance, or lower emission schemes. Those two systems compete in the market; retailers in both EPOS and EPSS aim to maximize profit from investing in renewable energy, although in the former they rely on electricity sales and in the latter on servicing. They concluded that not only EPSS boosts investments in solar PV and battery storage, but also more revenue is generated compared to EPOS. The main barrier to EPSS is the low number of alternative-seeking consumers due to the cognitive bias which is threefold: loss-aversion bias, status quo bias, and social proof.

\subsection{Energy Consumption Feedback Using DR and Blockchain}

With the emergence of small scale prosumers and electric vehicles, peer to peer distributed energy trading (P2P DET) will become more dominant as utility companies' involvement will decrease. When prosumers have surplus generation, they can sell electricity to the utility grid or to other consumers. Blockchain can provide privacy and security for the transactions in the future energy trading platforms. Because users are identified with cryptographic keys instead of their names, transactions are anonymous. The electricity generation and consumption can be thus traded on the blockchain. The blockchain can be used in zones without delegation of authority for creating decentralized energy trading platforms, as the blockchain technology can make abstraction of the need for banks when performing commercial exchanges. Those platforms can promote the collective aggregation of DR; thus, load and electricity generation contribute to build an energy community. Indeed, the blockchain seems more appropriate for use in a secondary energy market. 
The blockchain is seen as a kind of integration technology that can support many AI and internet programs and mostly support decentralized organizations and microgrids.

Researchers can direct their future work towards elaborating solutions to societal and environmental problems while still providing economic profits in sustainable smart microgrid applications. Moreover, they could investigate most optimum DR scheduling for manufacturers; blockchain network settings and maximization of the demand, which is in order to build a more transparent and traceable relationship between energy sources and energy use. The blockchain energy market could be organized using different cryptocurrencies. On the other hand, it is important to consider the political factors and the volatility involved when using cryptocurrencies in the financial markets, to avoid shocks in the electricity market.

\section{Conclusions}

On the electricity grid, balance between generation and consumption must be maintained at all times while limiting power fluctuations causing grid stability issues. Demand response allows reduction of peak loads by shifting or reducing consumption upon notification from the grid operator. Demand response is either incentive-based, where participants surrender control of some of their load to the grid operator, or price-based, where participants react to electricity price signals; several dynamic pricing schemes are used. Real-time pricing is the most efficient structure; however, for fast balancing DR, contractual incentives in terms of dispatchable DR (direct load control) are more beneficial for the users. DR improves grid reliability and reduces the need for peaking plants often relying on natural gas. Moreover, because of the added demand-side flexibility, DR enables higher intermittent renewables and electric vehicles penetration rates because it contributes in the short term to align electricity generation and consumption. Moreover, it reduces the curtailment of renewables by allowing consumption load to be shifted to high generation periods. However, for power generation fluctuations over longer time frames, electricity storage is highly necessary. Furthermore, the DR potential is also dependent on the time slot. When smart meters allowing two-way communication between utility companies and consumers are set in place, demand response will become a major actor in the smart grid of the future. Policies are already in effect for massive deployment of smart meters, smart plugs, and mobile apps for wide spreading of DR and DSM. The present work reviewed literature on demand response related research published during the 2010-2020 period. Based on a combination of strategic keywords, 81 publications were selected to write this review. Most studies relate to DR models and load scheduling and few elaborate on costs and barriers. The key parameters are load scheduling capacity, tariffing, incentives, and implementation potential and barriers. Most studies describe optimization of the demand response procedure in order to reduce the electricity bills under different pricing schemes without significantly impairing user comfort. Most publications covered the residential sector because of the significant aggregated demand response potential of home appliances and HVAC systems, and also because of the relative flexibility of home appliances. Unleashing the potential of the residential sector must be done through aggregators so that individual smaller capacities can be aggregated and duly monetized in the electricity market. The barrier to implementation of DR in the residential sector is customer awareness and investment costs, while information campaigns and government incentives will help, introduction of EPSS could be a real game changer. Implementation within the industrial sector is of strategic importance because industrial DR yields lower response time in case of a surge than ramping up peaking generators. Electricity-intensive non-continuous processes have a tremendous DR potential. However, industrial DR must rely on rewarding incentives owing to the production losses that could result from load shifting because processes require precise timing. In addition, investments are also needed for installation of demand response compatible equipment and infrastructure. Indeed, the principal obstacle to $\mathrm{DR}$ in the industrial sector is the non-return on investment risk owing to a lack of tailored incentives. A major concern is also the fact that in countries where baseload generation 
comes from coal-fired power plants without carbon capture and storage, which is more emission intensive than peaking gas-fired power plants: valley filling could in certain cases actually result in more emissions; rebound peaks could also occur. Therefore, implementing a carbon tax is also necessary. It is also important to highlight the fact that energy efficiency measures for reducing consumption must be implemented as they require less investment costs than DR. Indeed, electric heating, which has tremendous DR potential, should be considered simultaneously with renovation of the buildings in terms of insulation. While few studies disclose actual DR field data, there is an obvious gap in the literature concerning costs and barriers and generally speaking concerning non-dispatchable DR. Additionally, the service sector and ancillary services are mentioned less in the literature. The future trend of DR research is leaning towards ML algorithms, including 5G communication networks and eventually technologies such as the blockchain.

Author Contributions: Conceptualization, H.-W.H. and M.-Y.L.; methodology, H.-W.H. and M.-C.C.; validation, E.B. and H.-W.H.; formal analysis, E.B.; investigation, E.B. and C.-Y.W.; resources, M.-Y.L. and C.-Y.W.; data curation, E.B. and H.-W.H.; writing-original draft preparation, E.B. and H.-W.H.; writing—review and editing, E.B.; visualization, E.B. and C.-Y.W.; supervision, H.-W.H. and M.-C.C.; project administration, H.-W.H.; funding acquisition, H.-W.H. and M.-Y.L. All authors have read and agreed to the published version of the manuscript.

Funding: This research was funded by Academia Sinica (Contract No. AS-SS-110-07-2) and Bureau of Energy (Grant 109-A0102) of the Republic of China, Taiwan for its financial support.

Institutional Review Board Statement: Not applicable.

Informed Consent Statement: Not applicable.

Data Availability Statement: Not applicable.

Conflicts of Interest: The authors declare no conflict of interest.

\section{References}

1. US Department of Energy, Office of Electricity. Benefits of Demand Response in Electricity Markets and Recommendations for Achieving Them; Report to the United States Congress; US Department of Energy, Office of Electricity: Washington, DC, USA, 2006.

2. Amrollahi, M.H.; Bathaee, S.M.T. Techno-economic optimization of hybrid photovoltaic/wind generation together with energy storage system in a stand-alone micro-grid subjected to demand response. Appl. Energy 2017, 202, 66-77. [CrossRef]

3. Zhang, X.; Hug, G.; Kolter, J.Z.; Harjunkoski, I. Model predictive control of industrial loads and energy storage for demand response. In Proceedings of the IEEE Power and Energy Society General Meeting (PESGM 2016), Boston, MA, USA, 17-21 July 2016; pp. 1-5.

4. Yang, P.; Chavali, P.; Nehorai, A. Parallel autonomous optimization of demand response with renewable distributed generators. In Proceedings of the 2012 IEEE Third International Conference on Smart Grid Communications (SmartGridComm), Tainan, Taiwan, 5-8 November 2012; pp. 55-60.

5. Deng, R.; Yang, Z.; Chow, M.Y.; Chen, J. A survey on demand response in smart grids: Mathematical models and approaches. IEEE Trans. Ind. Inform. 2015, 11, 570-582. [CrossRef]

6. Werminski, S.; Jarnut, M.; Benysek, G.; Bojarski, J. Demand side management using DADR automation in the peak load reduction. Renew. Sustain. Energy Rev. 2017, 67, 998-1007. [CrossRef]

7. Tranfield, D.; Denyen, D.; Palminder, S. Towards a Methodology for Developing Evidence-Informed Management Knowledge by Means of Systematic Review. Br. J. Manag. 2003, 14, 207-222. [CrossRef]

8. Siano, P. Demand response and smart grids-A survey. Renew. Sustain. Energy Rev. 2014, 30, 461-478. [CrossRef]

9. Müller, T.; Möst, D. Demand response potential: Available when needed? Energy Policy 2018, 115, 181-198. [CrossRef]

10. Ali, M.; Safdarian, A.; Lehtonen, M. Demand response potential of residential HVAC loads considering users preferences. In Proceedings of the IEEE PES Innovative Smart Grid Technologies, Europe, Istanbul, Turkey, 12-15 October 2014; pp. 1-6.

11. Rotger-Griful, S.; Jacobsen, R.H.; Nguyen, D.; Sørensen, G. Demand response potential of ventilation systems in residential buildings. Energy Build. 2016, 121, 1-10. [CrossRef]

12. Samad, T.; Kiliccote, S. Smart grid technologies and applications for the industrial sector. Comput. Chem. Eng. 2012, 47, 76-84. [CrossRef]

13. Federal Energy Regulatory Commission. Available online: https:/ / www.ferc.gov (accessed on 23 March 2021).

14. Kathan, D. Assessment of Demand Response and Advanced Metering; Federal Energy Regulatory Commission: Washington, DC, USA, 2009. 
15. Heitkoetter, W.; Schyska, B.U.; Schmidt, D.; Medjroubi, W.; Vogt, T.; Agert, C. Assessment of the regionalised demand response potential in Germany using an open source tool and dataset. Adv. Appl. Energy 2020, 1, 100001. [CrossRef]

16. Xu, W.; Zhou, D.; Huang, X.; Lou, B.; Liu, D. Optimal allocation of power supply systems in industrial parks considering multi-energy complementarity and demand response. Appl. Energy 2020, 275, 115407. [CrossRef]

17. Bego, A.; Li, L.; Sun, Z. Identification of reservation capacity in critical peak pricing electricity demand response program for sustainable manufacturing systems. Int. J. Energy Res. 2014, 38, 728-736. [CrossRef]

18. Cui, H.; Li, F.; Hu, Q.; Bai, L.; Fang, X. Day-ahead coordinated operation of utility-scale electricity and natural gas networks considering demand response based virtual power plants. Appl. Energy 2016, 176, 183-195. [CrossRef]

19. Parizy, E.S.; Bahrami, H.R.; Choi, S. A low complexity and secure demand response technique for peak load reduction. IEEE Trans. Smart Grid 2018, 10, 3259-3268. [CrossRef]

20. Ghazvini, M.A.F.; Soares, J.; Abrishambaf, O.; Castro, R.; Vale, Z. Demand response implementation in smart households. Energy Build. 2017, 143, 129-148. [CrossRef]

21. De Angelis, F.; Boaro, M.; Fuselli, D.; Squartini, S.; Piazza, F.; Wei, Q. Optimal home energy management under dynamic electrical and thermal constraints. IEEE Trans. Ind. Inform. 2012, 9, 1518-1527. [CrossRef]

22. Li, W.T.; Yuen, C.; Hassan, N.U.; Tushar, W.; Wen, C.K.; Wood, K.L.; Liu, X. Demand response management for residential smart grid: From theory to practice. IEEE Access 2015, 3, 2431-2440. [CrossRef]

23. Tang, R.; Wang, S. Model predictive control for thermal energy storage and thermal comfort optimization of building demand response in smart grids. Appl. Energy 2019, 242, 873-882. [CrossRef]

24. Qayyum, F.A.; Naeem, M.; Khwaja, A.S.; Anpalagan, A.; Guan, L.; Venkatesh, B. Appliance scheduling optimization in smart home networks. IEEE Access 2015, 3, 2176-2190. [CrossRef]

25. Aalami, H.A.; Moghaddam, M.P.; Yousefi, G.R. Demand response modeling considering interruptible/curtailable loads and capacity market programs. Appl. Energy 2010, 87, 243-250. [CrossRef]

26. Brown, T.; Newell, S.A.; Oates, D.L.; Spees, K. International Review of Demand Response Mechanisms; The Brattle Group: London, $\mathrm{UK}, 2015$.

27. Shoreh, M.H.; Siano, P.; Shafie-khah, M.; Loia, V.; Catalão, J.P. A survey of industrial applications of Demand Response. Electr. Power Syst. Res. 2016, 141, 31-49. [CrossRef]

28. Valdes, J.; González, A.B.P.; Camargo, L.R.; Fenández, M.V.; Macia, Y.M.; Dorner, W. Industry, flexibility, and demand response: Applying German energy transition lessons in Chile. Energy Res. Soc. Sci. 2019, 54, 12-25. [CrossRef]

29. Karlsen, S.S.; Hamdy, M.; Attia, S. Methodology to assess business models of dynamic pricing tariffs in all-electric houses. Energy Build. 2020, 207, 109586. [CrossRef]

30. Martin, K.; Jokisalo, J.; Kosonen, R.; Alimohammadisagvand, B. Demand response of space heating and ventilation-Impact on indoor environmental quality. In Proceedings of the Roomvent \& Ventilation 2018, Espoo, Finland, 2-5 June 2018 ; pp. $121-162$.

31. Hu, M.; Xiao, F. Price-responsive model-based optimal demand response control of inverter air conditioners using genetic algorithm. Appl. Energy 2018, 219, 151-164. [CrossRef]

32. Ren, D.; Li, H.; Ji, Y. Home energy management system for the residential load control based on the price prediction. In Proceedings of the IEEE Online Conference on Green Communications, Online, 26-29 September 2011; pp. 1-6.

33. Olsen, D.; Goli, S.; Faulkner, D.; McKane, A. Opportunities for Energy Efficiency and Demand Response in the California Cement Industry. PIER Industrial/Agricultural/Water End-Use Energy Efficiency Program; eScholarship Open Access Publications; Lawrence Berkeley National Laboratory, University of California: Berkeley, CA, USA, 2010.

34. Klaassen, E.A.M.; Kobus, C.B.A.; Frunt, J.; Slootweg, J.G. Responsiveness of residential electricity demand to dynamic tariffs: Experiences from a large field test in the Netherlands. Appl. Energy 2016, 183, 1065-1074. [CrossRef]

35. Rieger, A.; Thummert, R.; Fridgen, G.; Kahlen, M.; Ketter, W. Estimating the benefits of cooperation in a residential microgrid: A data-driven approach. Appl. Energy 2016, 180, 130-141. [CrossRef]

36. Torriti, J. Demand Side Management for the European Supergrid: Occupancy variances of European single-person households. Energy Policy 2012, 44, 199-206. [CrossRef]

37. Alimohammadisagvand, B.; Jokisalo, J.; Sirén, K. The potential of predictive control in minimizing the electricity cost in a heat-pump heated residential house. In Proceedings of the 3rd IBPSA-England Conference Building Simulation \& Optimization, Newcastle, UK, 12-14 September 2016.

38. Pereira, R.; Fagundes, A.; Melício, R.; Mendes, V.M.F.; Figueiredo, J.; Martins, J.; Quadrado, J.C. A fuzzy clustering approach to a demand response model. Int. J. Electr. Power Energy Syst. 2016, 81, 184-192. [CrossRef]

39. Rodríguez-García, J.; Alvarez-Bel, C.; Carbonell-Carretero, J.F.; Alcázar-Ortega, M.; Peñalvo-López, E. A novel tool for the evaluation and assessment of demand response activities in the industrial sector. Energy 2016, 113, 1136-1146. [CrossRef]

40. Yi, W.; Zhang, Y.; Zhao, Z.; Huang, Y. Multiobjective robust scheduling for smart distribution grids: Considering renewable energy and demand response uncertainty. IEEE Access 2018, 6, 45715-45724. [CrossRef]

41. Good, N. Using behavioural economic theory in modelling of demand response. Appl. Energy 2019, 239, 107-116. [CrossRef]

42. Yalcin, Y.; Yigit, K.; Acarkan, B. Energy management of water transfer stations by using demand response programs. In Proceedings of the 6th International Conference on Control Engineering \& Information Technology (CEIT), Istanbul, Turkey, 25-27 October 2018; pp. 1-5. 
43. Nilsson, A.; Lazarevic, D.; Brandt, N.; Kordas, O. Household responsiveness to residential demand response strategies: Results and policy implications from a Swedish field study. Energy Policy 2018, 122, 273-286. [CrossRef]

44. Tahir, M.F.; Chen, H.; Khan, A.; Javed, M.S.; Cheema, K.M.; Laraik, N.A. Significance of demand response in light of current pilot projects in China and devising a problem solution for future advancements. Technol. Soc. 2020, 63, 101374. [CrossRef]

45. Directive (EU) 2019/944 of the European Parliament and of the Council of 5 June 2019 on Common Rules for the Internal Market for Electricity and Amending Directive 2012/27/EU (Text with EEA Relevance). Available online: https: / / eur-lex.europa.eu/eli/ $\operatorname{dir} / 2019 / 944 /$ oj (accessed on 12 January 2022).

46. Cobelo, I.; Rodriguez, J.E.; Boyra, M.; Anduaga, J.; Castellanos, A. Economical and technical viability of demand response in the Spanish power system: The "OPTIGES" project. In Proceedings of the CIRED Seminar 2008: SmartGrids for Distribution, Frankfurt, Germany, 23-24 June 2008; pp. 1-4.

47. Sharifi, R.; Fathi, S.H.; Anvari-Moghaddam, A.; Guerrero, J.M.; Vahidinasab, V. An economic customer-oriented demand response model in electricity markets. In Proceedings of the 2018 IEEE International Conference on Industrial Technology (ICIT), Lyon, France, 19-22 February 2018; pp. 1149-1153.

48. Märkle-Huß, J.; Feuerriegel, S.; Neumann, D. Large-scale demand response and its implications for spot prices, load and policies: Insights from the German-Austrian electricity market. Appl. Energy 2018, 210, 1290-1298. [CrossRef]

49. Eid, C.; Koliou, E.; Valles, M.; Reneses, J.; Hakvoort, R. Time-based pricing and electricity demand response: Existing barriers and next steps. Util. Policy 2016, 40, 15-25. [CrossRef]

50. Kohlhepp, P.; Harb, H.; Wolisz, H.; Waczowicz, S.; Müller, D.; Hagenmeyer, V. Large-scale grid integration of residential thermal energy storages as demand-side flexibility resource: A review of international field studies. Renew. Sustain. Energy Rev. 2019, 101, 527-547. [CrossRef]

51. Jayantilal, P.H.; Shah, N.E.H.A. A review on electrical energy management techniques for supply and consumer side in industries. Int. J. Sci. Eng. Technol. Res. 2014, 3, 550-556.

52. Müller, F.L.; Jansen, B. Large-scale demonstration of precise demand response provided by residential heat pumps. Appl. Energy 2019, 239, 836-845. [CrossRef]

53. Bui, V.H.; Hussain, A.; Kim, H.M. A multiagent-based hierarchical energy management strategy for multi-microgrids considering adjustable power and demand response. IEEE Trans. Smart Grid 2016, 9, 1323-1333. [CrossRef]

54. Yao, L.; Lim, W.H.; Tsai, T.S. A real-time charging scheme for demand response in electric vehicle parking station. IEEE Trans. Smart Grid 2016, 8, 52-62. [CrossRef]

55. Yang, S.C. The Survey of Characteristic of Participants in Demand Response; Taiwan Power Research Institute: Taipei, China, 2019.

56. Stede, J.; Arnold, K.; Dufter, C.; Holtz, G.; von Roon, S.; Richstein, J.C. The role of aggregators in facilitating industrial demand response: Evidence from Germany. Energy Policy 2020, 147, 111893. [CrossRef]

57. Vuelvas, J.; Ruiz, F. A novel incentive-based demand response model for Cournot competition in electricity markets. Energy Syst. 2019, 10, 95-112. [CrossRef]

58. Torriti, J.; Hassan, M.G.; Leach, M. Demand response experience in Europe: Policies, programmes and implementation. Energy 2010, 35, 1575-1583. [CrossRef]

59. Gils, H.C. Assessment of the theoretical demand response potential in Europe. Energy 2014, 67, 1-18. [CrossRef]

60. Ozturk, Y.; Senthilkumar, D.; Kumar, S.; Lee, G. An intelligent home energy management system to improve demand response. IEEE Trans. Smart Grid 2013, 4, 694-701. [CrossRef]

61. Chuan, L.; Ukil, A. Modeling and validation of electrical load profiling in residential buildings in Singapore. IEEE Trans. Power Syst. 2014, 30, 2800-2809. [CrossRef]

62. Bitaraf, H.; Rahman, S. Reducing curtailed wind energy through energy storage and demand response. IEEE Trans. Sustain. Energy 2017, 9, 228-236. [CrossRef]

63. Dehnavi, E.; Abdi, H. Determining optimal buses for implementing demand response as an effective congestion management method. IEEE Trans. Ind. Inform. 2016, 32, 1537-1544. [CrossRef]

64. Torstensson, D.; Wallin, F. Potential and barriers for demand response at household customers. Energy Procedia 2015, 75, 1189-1196. [CrossRef]

65. Singaravelan, A.; Kowsalya, M. A novel minimum cost maximum power algorithm for future smart home energy management. $J$. Adv. Res. 2017, 8, 731-741. [CrossRef]

66. Paterakis, N.G.; Erdinc, O.; Bakirtzis, A.G.; Catalão, J.P. Optimal household appliances scheduling under day-ahead pricing and load-shaping demand response strategies. IEEE Trans. Ind. Inform. 2015, 11, 1509-1519. [CrossRef]

67. Shakeri, M.; Shayestegan, M.; Abunima, H.; Reza, S.S.; Akhtaruzzaman, M.; Alamoud, A.R.M.; Amin, N. An intelligent system architecture in home energy management systems (HEMS) for efficient demand response in smart grid. Energy Build. 2017, 138, 154-164. [CrossRef]

68. Hussain, I.; Mohsin, S.; Basit, A.; Khan, Z.A.; Qasim, U.; Javaid, N. A Review on Demand Response: Pricing, Optimization, and Appliance Scheduling. Procedia Comput. Sci. 2015, 52, 843-850. [CrossRef]

69. Jordehi, A.R. Optimisation of demand response in electric power systems, a review. Renew. Sustain. Energy Rev. 2019, 103, 308-319. [CrossRef]

70. Pang, Y.; He, Y.; Jiao, J.; Cai, H. Power load demand response potential of secondary sectors in China: The case of western Inner Mongolia. Energy 2020, 192, 116669. [CrossRef] 
71. Starke, M.R.; Alkadi, N.E.; Letto, D.; Johnson, B.; Dowling, K.; George, R.; Khan, S. Demand-Side Response from Industrial Loads; Oak Ridge National Lab (ORNL): Oak Ridge, TN, USA, 2013.

72. Liu, Z.; Wierman, A.; Chen, Y.; Razon, B.; Chen, N. Data center demand response: Avoiding the coincident peak via workload shifting and local generation. Perform. Eval. 2013, 70, 770-791. [CrossRef]

73. Hui, H.; Ding, Y.; Shi, Q.; Li, F.; Song, Y.; Yan, J. 5G network-based Internet of Things for demand response in smart grid: A survey on application potential. Appl. Energy 2020, 257, 113972. [CrossRef]

74. Dranka, G.G.; Ferreira, P. Review and assessment of the different categories of demand response potentials. Energy 2019, 179, 280-294. [CrossRef]

75. Aryandoust, A.; Lilliestam, J. The potential and usefulness of demand response to provide electricity system services. Appl. Energy 2017, 204, 749-766. [CrossRef]

76. Barbierato, L.; Estebsari, A.; Pons, E.; Pau, M.; Salassa, F.; Ghirardi, M.; Patti, E. A distributed IoT infrastructure to test and deploy real-time demand response in smart grids. IEEE Internet Things J. 2018, 6, 1136-1146. [CrossRef]

77. Radenković, M.; Bogdanović, Z.; Despotović-Zrakić, M.; Labus, A.; Lazarević, S. Assessing consumer readiness for participation in IoT-based demand response business models. Technol. Forecast. Soc. Chang. 2020, 150, 119715. [CrossRef]

78. Gholian, A.; Mohsenian-Rad, H.; Hua, Y. Optimal industrial load control in smart grid. IEEE Trans. Smart Grid 2015, 7, 2305-2316. [CrossRef]

79. Neves, D.; Silva, C.A. Optimal electricity dispatch on isolated mini-grids using a demand response strategy for thermal storage backup with genetic algorithms. Energy 2015, 82, 436-445. [CrossRef]

80. Bossmann, T.; Eser, E.J. Model-based assessment of demand-response measures-A comprehensive literature review. Renew. Sustain. Energy Rev. 2016, 57, 1637-1656. [CrossRef]

81. Vivekananthan, C.; Mishra, Y.; Ledwich, G.; Li, F. Demand response for residential appliances via customer reward scheme. IEEE Trans. Smart Grid 2014, 5, 809-820. [CrossRef]

82. Firouzmakan, P.; Hooshmand, R.A.; Bornapour, M.; Khodabakhshian, A. A comprehensive stochastic energy management system of micro-CHP units, renewable energy sources and storage systems in microgrids considering demand response programs. Renew. Sustain. Energy Rev. 2019, 108, 335-368. [CrossRef]

83. Ghasemi, A.; Enayatzare, M. Optimal energy management of a renewable-based isolated microgrid with pumped-storage unit and demand response. Renew. Energy 2018, 123, 460-474. [CrossRef]

84. Derakhshan, G.; Shayanfar, H.A.; Kazemi, A. The optimization of demand response programs in smart grids. IEEE Trans. Ind. Inform. 2016, 94, 295-306. [CrossRef]

85. Setlhaolo, D.; Xia, X.; Zhang, J. Optimal scheduling of household appliances for demand response. Electr. Power Syst. Res. 2014, 116, 24-28. [CrossRef]

86. Vázquez-Canteli, J.R.; Nagy, Z. Reinforcement learning for demand response: A review of algorithms and modeling techniques. Appl. Energy 2019, 235, 1072-1089. [CrossRef]

87. Antonopoulos, I.; Robu, V.; Couraud, B.; Kirli, D.; Norbu, S.; Kiprakis, A.; Flynn, D.; Elizondo-Gonzalez, S.; Wattam, S. Artificial intelligence and machine learning approaches to energy demand-side response: A systematic review. Renew. Sustain. Energy Rev. 2020, 130, 109899. [CrossRef]

88. Esnaola-Gonzalez, I.; Diez, F.J. Integrating Building and IoT data in Demand Response solutions. In Proceedings of the 7th Linked Data in Architecture and Construction Workshop, Lisbon, Portugal, 19-21 June 2019.

89. Kusumaningdyah, W.; Tezuka, T.; McLellan, B.C. Investigating Preconditions for Sustainable Renewable Energy Product-Service Systems in Retail Electricity Markets. Energies 2021, 14, 1877. [CrossRef] 